\title{
DISPONIBILIDADE DE FERRO EM GRÃOS DE FEIJÃO COMUM (Phaseolus vulgaris L.) IRRADIADOS
}

\section{PRISCILA BRIGIDE}

\author{
Dissertação apresentada à Escola Superior de \\ Agricultura "Luiz de Queiroz", Universidade de São \\ Paulo, para obtenção do título de Mestre em Ciências, \\ Área de Concentração: Ciência e Tecnologia de \\ Alimentos
}

PIRACICABA

Estado de São Paulo - Brasil

Fevereiro - 2002 


\section{DISPONIBILIDADE DE FERRO EM GRÃOS DE FEIJÃO COMUM (Phaseolus vulgaris L.) IRRADIADOS}

PRISCILA BRIGIDE

Nutricionista

Orientadora: $\operatorname{Prof}^{\mathrm{a}}{ }^{\mathrm{Dr}}{ }^{\mathrm{a}}$. SOLANGE GUIDOLIN CANNIATTI-BRAZACA

Dissertação apresentada à Escola Superior de Agricultura "Luiz de Queiroz", Universidade de São Paulo, para obtenção do título de Mestre em Ciências, Área de Concentração: Ciência e Tecnologia de Alimentos

PIRACICABA

Estado de São Paulo - Brasil

Fevereiro - 2002 
Dados Internacionais de Catalogação na Publicação (CIP) DIVISÃO DE BIBLIOTECA E DOCUMENTAÇÃO - ESALQ/USP

\section{Brigide, Priscila}

Disponibilidade de ferro em grãos de feijão comum (Phaseolus vulgaris L.) irradiados / Priscila Brigide. - - Piracicaba, 2002.

$58 \mathrm{p}$.

Dissertação (mestrado) - - Escola Superior de Agricultura Luiz de Queiroz, 2002.

Bibliografia.

1. Feijão 2. Ferro 3. I rradiação de alimento I. Título

CDD 635.652

"Permitida a cópia total ou parcial deste documento, desde que citada a fonte - $O$ autor" 


\section{DEDICO}

Ao meu pai Lauriberti e a minha mãe Maria Helena, dedico esta conquista com o mais profundo respeito, admiração, amor e minha eterna gratidão.

Aos meus irmãos Cintia, Giuliano e Lauriberti Filho, pela presença constante em minha vida. 
Ao Moisés de Melo Santana

Agradeço- te por iluminar o meu caminho, com todo amor 


\section{AGRADECIMENTOS}

A Deus,

pela existência da vida

À Prof ${ }^{a}$. Dr ${ }^{a}$ Solange Guidolim Canniatti- Brazaca

pelos ensinamentos, dedicação e apoio no decorrer de todo o trabalho

À Prof ${ }^{a}$. Dr ${ }^{a}$ Marília Oeterrer,

pelo incentivo ao meu ingresso à pesquisa e seu eterno espírito de colaboração

À tecníca de laboratório Maria de Lourdes Perin Storer

pela colaboração e execução do trabalho

À secretária Raquel Iracema de Silva

pela amizade e pelos serviços prestados

À bibliotecária Beatriz Helena Giongo

pela revisão das referências bibliográficas e todo o serviço prestado

À Marisa A. Vergili

que de um modo todo especial, me incentivou a conquista

À Vanessa Maestro

pela amizade constante, apoio e incentivos 


\section{À Márcia Hebling \\ pela amizade, colaboração e auxílio na elaboração da apresentação}

\section{À Zaide Clemente}

pela amizade, apoio e auxílio espiritual

Às amigas Maria Helena Frias, Fabiana C. Gonçalves, Eliana F. de Oliveira, Cristiane Stolf, Luciana Chill

pela amizade "eterna"

Ao Prof. Dr. Quirino Augusto de Camargo Carmello e técnicos do laborátorio de nutrição de plantas

pela realização da análise de minerais

À Companhia Brasileira de Esterilização (CBE)

pela irradiação dos grãos

Aos professores, funcionários, colegas e amigos que direta ou indiretamente colaboraram na efetivação deste trabalho. 


\section{SUMÁRIO}

\begin{tabular}{|c|c|}
\hline & Página \\
\hline LISTA DE FIGURAS... & ix \\
\hline LISTA DE TABELAS... & $\mathrm{x}$ \\
\hline RESUMO........................ & $\mathrm{x}$ \\
\hline SUMMARY ..................... & xiii \\
\hline 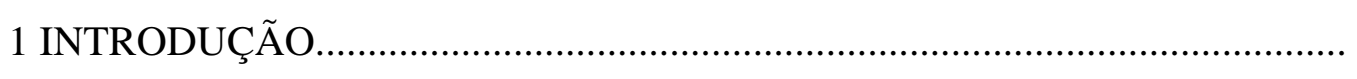 & 1 \\
\hline 2 REVISÃO DE LITERATURA..................... & 4 \\
\hline 2.1Biodisponibilidade................................. & 4 \\
\hline 2.2 Absorção de ferro...... & 5 \\
\hline 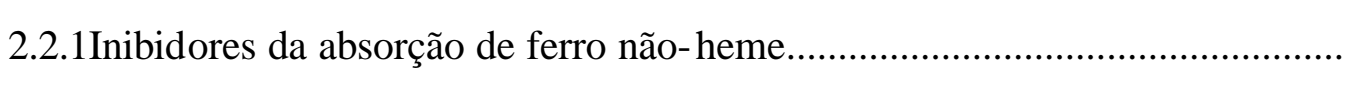 & 8 \\
\hline 2.2.2 Estimuladores da absorção de ferro não-heme..... & 11 \\
\hline 2.3 Anemia............................. & 12 \\
\hline 2.4 Fontes alimentares de ferro. & 14 \\
\hline 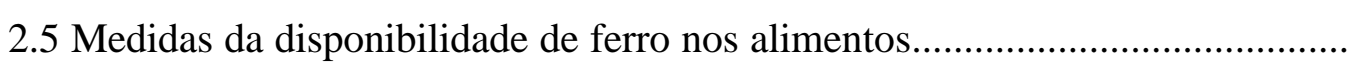 & 14 \\
\hline 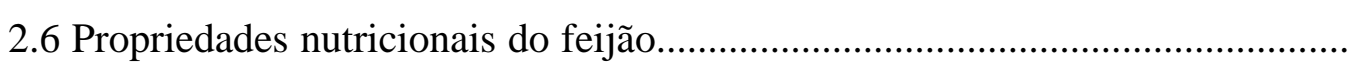 & 15 \\
\hline 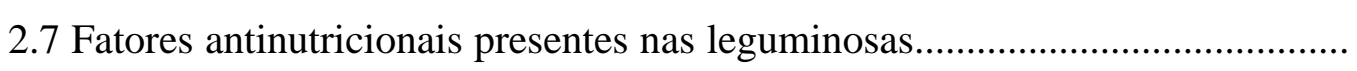 & 17 \\
\hline 2.8 Alteração nos nutrientes do feijão com a manipulação e/ ou processamento... & 18 \\
\hline 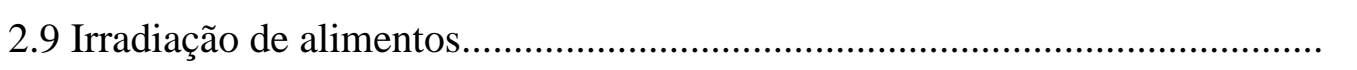 & 22 \\
\hline 3 MATERIAL E MÉTODOS......... & 25 \\
\hline 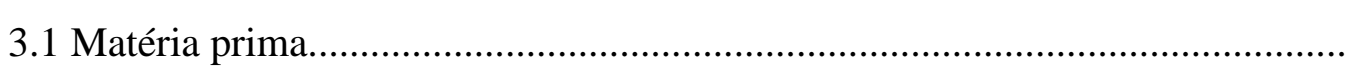 & 25 \\
\hline 3.2. Análises químicas............... & 25 \\
\hline 3.2.1 Preparo das amostras............. & 25 \\
\hline 3.2.2 Composição centesimal.. & 26 \\
\hline
\end{tabular}




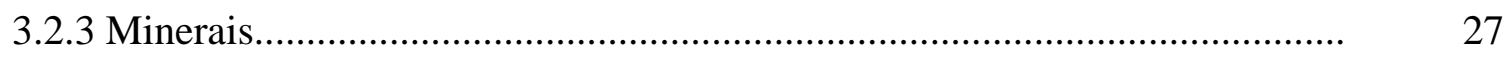

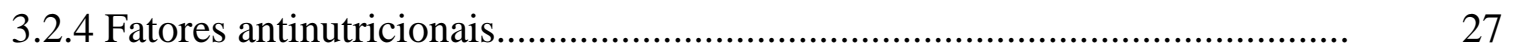

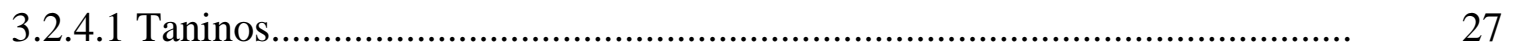

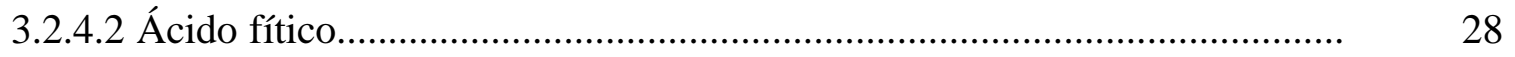

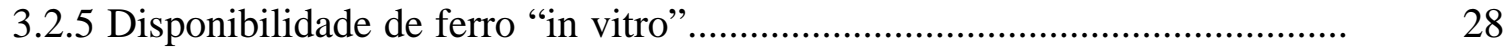

3.3 Análise Estatísitica............................................................................... 28

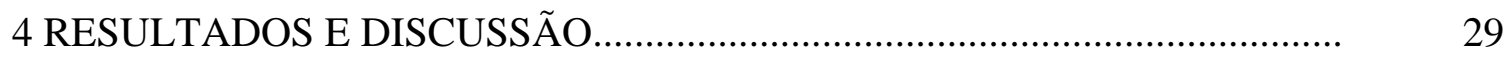

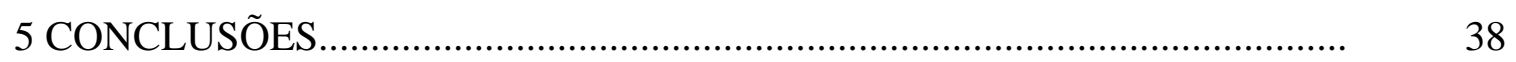

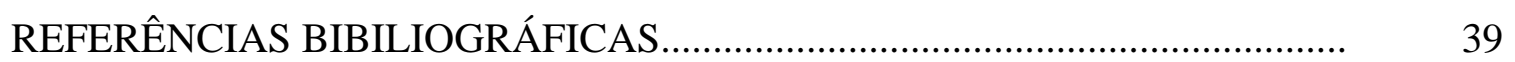




\section{LISTA DE FIGURAS}

Página

1 Composição centesimal dos grãos de feijão cru e

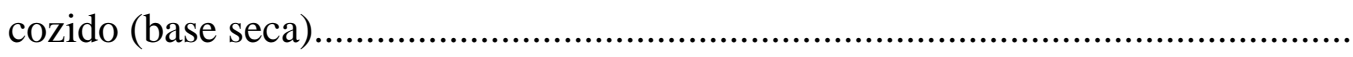

2 Concentrações de taninos dos feijões irradiados da

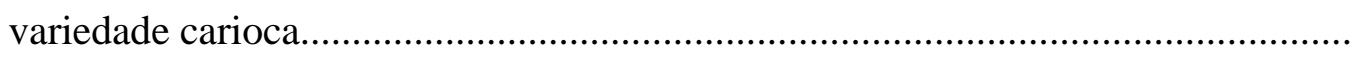

3 Concentrações de fitatos dos feijões irradiados da

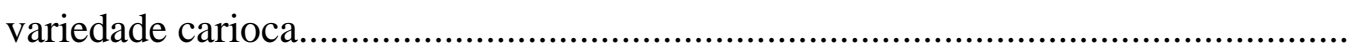




\section{LISTA DE TABELAS}

Página

1 Concentrações de minerais do feijão irradiado da variedade carioca cru.................. 32

2 Concentrações de minerais do feijão irradiado da variedade carioca cozidos............ 32 


\title{
DISPONIBILIDADE DE FERRO EM GRÃOS DE FEIJÃO COMUM (Phaseolus vulgaris L.) IRRADIADOS
}

\author{
Autora: PRISCILA BRIGIDE \\ Orientadora: Prof ${ }^{\mathrm{a}}$. Dr ${ }^{\mathrm{a}}$ SOLANGE GUIDOLIN CANNIATTI- BRAZACA
}

\section{RESUMO}

O feijão é a leguminosa mais consumida no Brasil, porém, o rendimento médio da lavoura no Brasil é baixo, devido, entre outros fatores, a infestação dos grãos. Para combater essas perdas, o processo de irradiação é uma alternativa saudável, quando comparada aos tratamentos químicos. Esta pesquisa teve por objetivo avaliar a disponibilidade de ferro em feijão comum irradiado (doses de 0, 2, 6 e 10 kGy) cru e submetido à cocção. Foi realizada a determinação da composição centesimal, dos antinutricionais (taninos e fitatos) e da diálise de ferro pelo método "in vitro". A cocção diminuiu todos os itens da composição centesimal, com exceção dos carboidratos disponíveis, obtendo os seguintes teores: proteína 27,4 e 23,9; lipídeos 1,2 e 1,1; fibras 23,7 e 18,6, carboidratos 43,3 e 52,5, respectivamente, para grãos crus e cozidos. Houve também diminuição na quantidade de taninos a qual se correlacionou inversamente com as doses aplicadas, com exceção da dose de 2 kGy, variando de 1,56 (10 kGy) a 2,49 (2 kGy) para grãos crus e traços (10 kGy) a 0,103 (2 kGy) para grãos cozidos. Os teores de fitatos variaram de 4,63 (2 kGy) a 8,28 (0 kGy) e 5,29 (6 kGy) a 9,55 (0 kGy), respectivamente, para grãos crus e cozidos. Em relação ao ferro dialisado, os teores variaram de 1,16 (0 kGy a 2,39 (6 kGy) e 5,33 (0 kGy) a 8,02 (6 kGy), respectivamente, para grãos crus e cozidos. A irradiação com dose de $6 \mathrm{kGy}$ apresentou efeito positivo em relação à disponibilidade do ferro em feijão tanto cru como cozido, sendo recomendada para a utilização. 


\title{
AVAILABILITY OF IRON IN GRAINS COMMOM BEANS (Phaseolus vulgaris L.) IRRADIATED
}

\author{
Author : PRISCILA BRIGIDE \\ Adviser: Prof ${ }^{\mathrm{a}}$. Dr ${ }^{\mathrm{a}}$ SOLANGE GUIDOLIN CANNIATTI- BRAZACA
}

\section{SUMMARY}

Commom bean is the legume more consuming in Brazil, however, the average income of the farming in Brazil is low must the infestaction of the grains, to fight these losses the irradiation process is an alternative healthful if compared the chemical handlings. The objective of this research was evaluate the iron availability in irradiated raw and cooked beans (doses of $0,2,6$ and $10 \mathrm{kGy}$ ). It was carried through the centesimal composition, antinutritional factors (tannins and phytate) and iron dialyses for the method "in vitro". Cooking diminished the mainly components of the composition with exception of available carbohydrates, the protein content of 27.4 and 23.9 ; fat 1.2 and 1.1 ; fibre 23.7 and 18.6, carbohydrates 43.3 and 52.5; respectively for raw grains and cooked. It also had reduction in the amount of tannin which if correlated reversely with the applied doses, with exception of the dose of $2 \mathrm{kGy}$, varying of 1.56 (10 kGy) to 2.49 ( $2 \mathrm{kGy}$ ) to the for raw grains and traces $(10 \mathrm{kGy})$ to $0.103(2 \mathrm{kGy})$ for grains cooked. The phytate varied of 4.63 (2 kGy) to 8.28 (0 kGy) and 5.29 (6 kGy) to the 9.55 (0 kGy), respectively for raw grains and cooked. In relation to the dialysed iron, the content varied of 1.16 (0 kGy) to 2.39 (6 $\mathrm{kGy}$ ) and $5.33(0 \mathrm{kGy})$ to the 8.02 (6 kGy), respectively for raw grains and cooked The dose of $6 \mathrm{kGy}$ showed positive effect availability such as raw as cooked grain, it being recommended for the utilization. 


\section{INTRODUÇÃO}

Elementos minerais presentes em baixas concentrações nos tecidos são denominados de elementos-traço, microelementos ou microminerais; sendo considerados essenciais e benéficos ao organismo. O ferro é o microelemento mais abundante no organismo humano (Nielsen,1986; Carpenter \& Mahoney,1992).

Ao se tratar da absorção de nutrientes, deve-se levar em consideração a biodisponibilidade dos mesmos. Esta é definida como a proporção do nutriente na dieta ou no alimento que possa ser utilizado pelo organismo (Fairweather-Tait, 1992).

Há duas formas principais de ferro, denominadas ferro heme e ferro não-heme. $\mathrm{O}$ ferro heme é constituinte da hemoglobina, a qual transporta o oxigênio desde os pulmões até os tecidos; da mioglobina que armazena o oxigênio, que será utilizado na contração muscular e também componente de enzimas (citocromos, catalase e peroxidase). $\mathrm{O}$ ferro não-heme está presente nas proteínas ferro-sulfurosas e metaloflavoproteínas implicadas no metabolismo oxidativo (Carpenter \& Mahoney,1992; Martínez et al., 1999).

Em relação ao ferro, fatores como o tratamento térmico e/ou processamento podem influenciar sua biodisponibilidade nos alimentos. Entre os fatores dietéticos, estão aqueles que aumentam a absorção de ferro não-heme, tais como o ácido ascórbico e aminoácidos provenientes da carne, e aqueles que diminuem sua absorção, tais como os fitatos, polifenóis e o cálcio. A interação de todos esses intensificadores e inibidores é determinante na biodisponibilidade de ferro não-heme na refeição. Fatores intrínsecos do organismo, como por exemplo o estado nutricional do indivíduo, influenciam na absorção e, conseqüentemente, na biodisponibilidade do ferro (Benito \& Miller, 1998).

A deficiência de ferro é o problema nutricional de maior prevalência mundial,

ocorrendo tanto nos países desenvolvidos como nos países em desenvolvimento. Deve-se estabelecer se essa deficiência é devido à ingestão inadequada de ferro (deficiência de ferro primária), ou devido ao aumento da absorção de ferro exigido por várias condições fisiológicas e/ou patológicas, como por exemplo parasitismo hemorragias, treinamento físico intenso - (deficiência de ferro secundária) (Hambraeus, 1999). 
Segundo Martínez et al. (1999), a quantidade de ferro em leguminosas é de 5,3-8,5 mg/100g. O consumo médio per capita de feijão no Brasil é de aproximadamente 16 kg/habitante/ano, notando-se maior consumo na área rural do país (Roston, 1990).

O feijão tem especial importância no Brasil, não somente pelo país ser o maior produtor e consumidor mundial (2,2 a 2,5 milhões de toneladas, em aproximadamente 5 milhões de hectares cultivados), mas também por ser o feijão um dos principais alimentos protéicos do povo brasileiro (Roston, 1990; Gonçalves \& Souza, 1998). A produção de grãos no ano de 1995 foi de 2.946.267 toneladas no Brasil (Fundação..., 1996). Segundo dados do IBGE (2001), a produção total foi de 3.038.238 toneladas, referente ao ano de 2000.

Entretanto, ocorrem perdas desses grãos a cada colheita, devido, entre outros fatores, ao ataque de insetos e roedores, além da ocorrência de alterações das características físico-químicas, por transformações estruturais de seus componentes, resultando feijões que apresentam elevada resistência à cocção, com modificações das propriedades organolépticas e nutricionais (Mancini-Filho, 1990; Villavicencio, 1998).

Para combater essas perdas, o processo de irradiação dos feijões é uma alternativa mais atrativa e saudável, quando comparada aos tratamentos químicos, por exemplo, metil brometo. A aplicação da radiação ionizante, com o propósito de preservar e desinfestar grãos, surge como prática promissora, utilizada para estender a vida útil e reduzir as perdas das safras durante a armazenagem do produto. Os custos estimados dos benefícios da irradiação comercial, como tratamento, mostram ser competitivo com outros métodos de fumigação e outros tratamentos físicos e térmicos (Nascimento, 1992; Villavicencio, 1998).

As doses até $10 \mathrm{kGy}$ foram aplicadas, conforme Organização da Agricultura e Alimentos (FAO)/ Organização Mundial da Saúde (OMS) (2000), que asseguram a inocuidade dos alimentos sob ponto de vista microbiológico, nutricional e toxicológico, aplicando doses até $10 \mathrm{kGy}$.

Enfocando a irradiação no processamento de alimentos, visando à melhoria disponibilidade de ferro e os efeitos das doses de radiação de 0, 2, 6 e 10 kGy sobre alguns componentes dos feijões (Phaseolus vulgaris variedade carioca), tais como fitatos e taninos, esta pesquisa teve por objetivos: 
- avaliação do efeito das diferentes doses de radiação sobre a disponibilidade de ferro em feijões crus e cozidos;

- a caracterização dos feijões, sendo realizada a composição centesimal e de minerais em grãos crus e cozidos, verificando os efeitos dos processamentos de maceração e cocção;

- determinação do efeito da irradiação sobre taninos e fitatos presentes nos feijões. 


\section{REVISÃO DE LITERATURA}

\subsection{Biodisponibilidade}

Segundo National Research Council -NRC (1989), a quantidade recomendada da ingestão diária de ferro para homens é de $12 \mathrm{mg}$ para o agrupamento de menor idade (11 aos 18 anos) e $10 \mathrm{mg}$ para o grupamento de maior idade (19 anos em diante). Para as mulheres, na faixa etária dos 11 aos 50 anos, a quantidade é de $15 \mathrm{mg}$ e, a partir dos 51 anos, a necessidade diminui para10 $\mathrm{mg}$.

As dietas têm sido classificadas como sendo de alta (15\%), intermediária (10\%) e baixa (5\%) biodisponibilidade de ferro, dependendo da proporção de ferro-heme e da presença de inibidores e intensificadores da absorção de ferro não-heme. A dieta de baixa disponibilidade é caracterizada como dieta simples baseada em cereais e vegetais, quantidades insignificantes de peixe, carne (30 gr) e ácido ascórbico $(25 \mathrm{mg})$ presente nos alimentos. A dieta de biodisponibilidade intermediária é baseada também em cereais, vegetais ricos em ácido ascórbico e carne. A die ta de alta biodisponibilidade é uma dieta diversificada, contendo quantidades significantes de ácido ascórbico (75 mg), carne, ave ou peixe $(90 \mathrm{~g})$ e baixa quantidade do ácido fítico. Esse tipo de dieta pode facilmente ser classificada como intermediária, quando existe consumo de inibidores, tais como o chá, fibras e alimentos com elevado teor de cálcio (DeMayer et al,1989; FAO/OMS,1988).

A biodisponibilidade de um nutriente é influenciada por fatores distintos, que se classificam em intrínsecos (fisiológicos) e extrínsecos (dietéticos) (Southon et al., 1988).

Alguns dos fatores que podem afetar a biodisponibilidade de elementos traços são:

a) composição dietética- qualidade da proteína (proteína animal ou vegetal, balanço de aminoácidos), quantidade da proteína, quantidade do elemento traço, interações de 
nutrientes (elemento-elemento, composto-elemento orgânico), promotores (carne, ácido ascórbico, ácido cítrico, vitamina D, alguns aminoácidos e açúcares), inibidores (fitato, oxalato, polifenóis, fibra e goitrogênicos), deficiência de microcomponentes (ácido ascórbico, riboflavina e vitamina $\mathrm{E})$;

b) preparação ou processamento alimentar- cru, cozimento (vários métodos), fermentação, moagem;

c) fatores do indivíduo- idade, sexo, estado fisiológico (gravidez, lactação, atividade física), estado nutricional (moderada ou ostensiva deficiência), doença (incluindo parasitismo), formação étnica (tipo de alimento selecionado, área geográfica), situação econômica (quantidade de alimento selecionado) (House, 1999).

A biodisponibilidade dos nutrientes no organismo ocorre em três fases: biodisponibilidade no lúmen intestinal para absorção, absorção e/ou retenção no organismo e utilização pelo organismo. O processamento dos alimentos pode influenciar, alterando a quantidade e espécie de ferro no produto, em relação à matéria-prima (primeira fase). A segunda e terceira fases dependem do mecanismo homeostático e necessidades fisiológicas individuais do organismo (Fairweather-Tait, 1993).

\subsection{Absorção de ferro}

O ferro está presente em todas as células do organismo como constituinte da hemoglobina e mioglobina, e de muitas enzimas (enzimas envolvidas em reação de oxidação-redução). Em indivíduos normais, a hemoglobina, a mioglobina, o ferro contido nas enzimas e a quantidade de ferro estocado são aproximadamente $67,5 \% ; 3,5 \% ; 0,2 \%$ e $27 \%$, respectivamente, do ferro total contido no corpo (Fairbanks, 1994).

Ferritina e hemosiderina são as principais formas de estoque de ferro. O fígado, o baço e a medula óssea têm a mais alta concentração desses dois compostos (Morris, 1987).

A absorção de ferro é influenciada por uma variedade de fatores, entre eles, a concentração e a forma química do ferro ingerido, a presença de fatores na dieta que promovam ou inibam a absorção de ferro e o estado de ferro no organismo (Hallberg, 1981). Indivíduos anêmicos absorvem duas a três vezes mais do que indivíduos normais (Monsen et al., 1978). 
O processo de absorção envolve a retirada de nutrientes no lúmen intestinal, transferência do nutriente através da célula da mucosa e transporte das células para outros tecidos e órgãos. Para absorção, a ingestão de alimento, contendo o nutriente mineral, pode apresentar-se na forma solúvel, ocupando as células da mucosa diretamente, ou formar complexos solúveis com outros componentes convertidos no meio intestinal para absorção. O mecanismo de absorção do ferro da dieta, através das células da mucosa gastrointestinal, é dependente das formas principais de ferro, denominadas ferro não-heme e ferro heme (Clyd esdale, 1988; Larsen, 1992).

$\mathrm{O}$ ferro heme apresenta-se na forma iônica reduzida $\mathrm{Fe}^{+2}$ (ferroso), representando 40\%-55\% do ferro presente na carne bovina, aves ou peixes, formando parte das moléculas de hemoglobina e mioglobina, sendo altamente disponível. Esse tipo de ferro entra diretamente nas células da mucosa na forma de complexo ferro-porfirina, e sua absorção é determinada principalmente pelo nível de ferro corporal e, em pequena parte, por fatores dietéticos, possivelmente o cálcio. O ferro não-heme, predominante na forma iônica oxidada $\mathrm{Fe}^{+3}$ (férrico), é menos solúvel no organismo; encontra-se nos cereais, leguminosas, verduras. A biodisponibilidade de ferro não-heme é menor em relação ao ferro heme, sendo influenciada por fatores dietéticos, além do nível do ferro corpóreo. O ferro não-heme, em meio ácido, é transportado quelado, aumentando a absorção na membrana do duodeno, facilitando a transferência do ferro através das microvilosidades da membrana (Hallberg et al., 1992; House \& Welch, 1987; Schricker et al., 1982; FAO/OMS, 1988).

A primeira etapa da absorção do ferro é representada pela passagem do ferro do lúmen para as células da mucosa. O ferro deve estar disponível no lúmen do duodeno para entrar no enterócito. A maior parte do ferro inorgânico dos alimentos está na forma férrica, a qual se precipita a $\mathrm{pH}$ abaixo de 3 , se não estiver na forma de quelato. Pouco se conhece sobre as diferentes formas de ferro presentes no duodeno durante a digestão (Benito \& Miller, 1998).

Conrad et al. (1991) concluíram que as mucinas desempenham papel importante para que o ferro esteja disponível para absorção nos enterócitos. A mucina se liga ao ferro em pH ácido e mantém o ferro em solução em pH neutro. Em experimento "in vivo", ferro na forma de radioíon ligou-se às mucinas e essa quelação foi absorvida na ausência de 
outro quelato. Constataram que o ferro que não formou quelato com a mucina no lúmen intestinal precipitou e foi pouco absorvida. A forma férrica do ferro solubilizado em ácido se liga à mucina gástrica, a qual mantém ferro solúvel e disponível pela penetração na mucosa do intestino delgado. Os autores também propõem que alguns componentes dietéticos (açúcares, polióis, aminas e aminoácidos) que formam quelatos instáveis podem servir como doadores de ferro para mucina em pH neutro, aumentando a absorção do ferro. Entretanto, há alguns constituintes dietéticos (carbonatos, oxalatos, fitatos, taninos) os quais formam precipitados com ferro ou quelatos estáveis interferindo na ligação entre ferro e mucinas, podendo diminuir sua absorção.

Dois caminhos da absorção do ferro foram identificados (Benito \& Miller, 1998).

O principal caminho para absorção de ferro no duodeno é dependente de energia, com carreador envolvendo uma proteína de transporte através da membrana. Isso foi evidenciado em fragmentos de duodeno de rato. Quando o oxigênio e a glicose estão ausentes ocorre inibição da absorção (Raja et al., 1989; Conrad et al., 1991).

O segundo caminho para captação do ferro foi proposto por Simpson et al. (1988, 1989), após constatar que o ácido graxo aumenta significantemente a captação do ferro pelas vesículas da borda em escova. O processo envolve a formação de um complexo FeIIácido graxo que poderia ser transferido através da membrana. Esse caminho possui uma reação adaptável limitada ao aumento da demanda de ferro, podendo acontecer em paralelo com o transporte de ferro dependente de energia já mencionado, e somente contribuiria para a abosrção do ferro (Peters et al., 1992; Simpson et al., 1989).

Além dos dois caminhos mencionados, há um terceiro caminho de transporte de ferro, porém de menor importância envolvendo a rota paracelular (entre as células) (Simpson et al., 1989). Apesar de pouca consideração desse caminho, quantidades significantes podem ser absorvidas, quando a quantidade de ferro dietético é alta, porque não há regulação adaptável para essa rota (Benito \& Miller,1998).

Há dois carreadores distintos no microvilos para o ferro não-heme, um para Fe II e outro para FeIII, já que as propriedades físico-químicas desses dois íons são diferentes (Simpson et al., 1986). Os caminhos eletrogênicos requerem quelação do ferro em complexos na superficie da mucosa antes de sua absorção, embora não haja concordância sobre o ferro Fe III entrar na célula dessa maneira ou se há necessidade de ser reduzido para 
FeII primeiro. Acredita-se que a redução do FeIII ao Fe II acontece antes da absorção (Raja et al., 1991). Provavelmente a maior parte do ferro II que entrou na célula será oxidado a ferro III (Benito \& Miller, 1998).

O ferro heme é absorvido de maneira mais eficiente que o não-heme, ainda que, em dietas com alta quantidade de carne, ocorrem de 10 a $15 \%$ da absorção em relação à ingestão total de ferro presente da dieta (Fairweather-Tait, 1992; Torre et al., 1991). O ferro presente nos feijões é o ferro não-heme, encontrado principalmente na forma férrica $\left(\mathrm{Fe}^{+3}\right)$.

A quantidade de ferro estocado no organismo é importante porque afeta a absorção alimentar de ferro. O conteúdo de ferro no organismo é controlado, principalmente pelo mecanismo homeostático de regulação e pelas necessidades fisiológicas individuais no organismo (Anderson, 1996; Fairwheather- Tait, 1993).

O fator mais importante que regula a absorção corporal é a própria necessidade corpórea de ferro, ou seja, quanto maior redução da quantidade de ferro depositado nos lugares distintos de reserva no organismo, tanto maior é a quantidade absorvida no trato intestinal, e vice-versa. A homeostase de ferro é controlada, em primazia, pela absorção e, secundariamente, pela excreção. A capacidade da mucosa em absorver o ferro depende da presença de receptores do cátion, na superfície da mucosa do epitélio intestinal; uma vez no citoplasma do enterócito, o ferro passa à membrana serosa e é transferido à corrente circulatória, através de uma série de processos regulatórios, cujos mecanismos não são totalmente conhecidos (Linder, 1988).

Tanto a composição dietética quanto a forma na qual o ferro está presente no trato gastro intestinal exercem influência na eficiência da absorção do ferro (Carpenter \& Mahoney,1992). Para ser absorvido, o ferro precisa atingir a parte superior do intestino delgado na forma solúvel. A solubilidade é pré-requisito para a absorção pelo intestino (Cook, 1977).

\subsubsection{Inibidores da absorção de ferro não-heme}

A suplementação de cálcio, como sal inorgânico ou produtos de laticínios, interfere de forma negativa na absorção de ferro pelos indivíduos, pois tanto o ferro heme como o não-heme são prejudicados pelo cálcio, atuando no transporte de ferro, através das células da mucosa (Hallberg et al,1993). 
A absorção de ferro apresenta maior eficiência quando há redução da ingestão de produtos de laticínios presentes, ou seja, é necessário reavaliar refeições que contenham ferro e a redistribuição diária da ingestão de cálcio em refeições com menor quantidade de ferro (Hallberg et al., 1992; Gleerup et al., 1995).

Alguns fatores dietéticos e/ou componentes que influenciam, negativamente, na absorção de ferro não-heme em indivíduos ou experimentos com animais, incluem: interações com elementos minerais, devido às propriedades físico-químicos similares ou absorção competitiva (Fairweather-Tait et al., 1995); proteínas de fontes animais ou vegetais (Hurrell et al.,1988); compostos polifenólicos, tais como taninos (Disler et al., 1975); saponinas (Price et al., 1989); lectinas (Migita, 1988); estágio de maturidade da planta (Welch et al, 1973) e fitatos (Torre et al., 1991).

Compostos polifenólicos são classificados como ácidos fenólicos e derivados, taninos e flavonóides. O termo taninos é utilizado para designar um grupo de substâncias com propriedades comuns, mas com estruturas diferentes. Os taninos, com base em suas características estruturais, são classificados em dois diferentes grupos: hidrolisáveis e condensados. Os hidrolisáveis são aqueles que, por hidrólise ácida, alcalina ou enzimática, liberam carboidratos (geralmente glicose) e fenólicos como o ácido gálico, diferenciando dos condensados, os quais liberam carboidratos (Salunkhe et al., 1982).

Os taninos dos feijões estão localizados principalmente na casca, e quantidades mínimas são encontradas nos cotilédones (Salunkhe et al., 1982).

Taninos e outros compostos fenólicos na dieta podem formar complexo insolúvel com ferro, no trato intestinal e com isso reduzir a biodisponibilidade de ferro solúvel (Brune et al, 1989). Adicionalmente, taninos podem ferir a mucosa intestinal (Reddy et al., 1985), alterar secreções intestinais (Mitjavila et al., 1977), formar complexos insolúveis com proteína dietética (Reddy et al., 1985), e as enzimas proteolíticas podem ser inibidas (Salunkhe et al., 1990), havendo aumento de excreção de proteínas endógenas (Shahkhalili et al., 1990). Como resultado dos efeitos de taninos, proteínas dietéticas não digeridas e proteínas endógenas e peptídios podem irreversivelmente ligar-se ao ferro e diminuir sua absorção.

Os taninos presentes no chá e café são inquestionáveis inibidores da absorção de ferro, formando complexo insolúvel (Hallberg, 1981). 
Bravo et al. (1995) sugeriram que polifenóis poderiam ser considerados como constituintes de fibra dietética, devido às propriedades similares que apresentam. Vários tipos de fibra dietética provenientes de diferentes fontes podem formar complexo com ferro em experimentos "in vitro" (Torre et al., 1991; Carpenter \& Mahoney, 1992; Carnovale \& Lintas, 1995). Nenhuma fonte natural de fibras, tanto na forma de grão de cereais, nem os componentes de fibras, incluindo celulose, hemicelulose, pectina, lignina e gomas, parecem consistentemente afetar a absorção mineral em indivíduos ou animais de laboratório (Torre et al., 1991; Cook et al., 1997). Porém, Hallberg et al. (1992) relataram que as pectinas abundantes em frutos são capazes de reduzir a absorção intestinal de ferro formando complexo insolúvel, enquanto Gillooly et al. (1984) reportaram que a lignina e hemicelulose inibiram a absorção de ferro em indivíduos, ao passo que a pectina e a celulose mostraram efeito oposto. A fibra dietética afeta o tempo de trânsito intestinal (Schneeman \& Tietyen, 1994), mas a eficiência da absorção de ferro em ratos não foi afetada pela administração de agente farmacológico, que ora aumentou, ora diminuiu a razão de passagem de digestão, através do intestino delgado (Fairweather-Tait \& Wright, 1991). Resultados de estudos para avaliar a influência de fibra na biodisponibilidade de ferro são conflitantes, de qualquer maneira, não há muitas informações de estudos "in vivo" para manter o conceito de que fibra dietética inibe a absorção de mineral através de um mecanismo de quelífero (Frolich, 1995).

Gibson (1994) acredita que a maioria dos efeitos da fibra dietética na biodisponibilidade de minerais são devidos à presença dos fitatos nos alimentos.

O fitato, hexafosfato de mio-inositol, é um constituinte normal das sementes e sua principal função é a estocagem de fósforo (Kratzer \& Vohra, 1986).

Lolas \& Markakis (1975) determinaram o teor de ácido fítico de 50 variedades de feijões (Phaseolus vulgaris) e encontraram uma faixa de $0,54 \%$ a $1,58 \%$ do peso seco do grão, o que representa cerca de $54 \%$ a $82 \%$ do total de fósforo da semente. Além disso, um complexo de fitato-proteína foi isolado e os autores observaram também que cerca de $99 \%$ do total de ácido fítico apresentava-se solúvel em água.

A biodisponibilidade de ferro apresenta diminuição na presença de fitatos, devido à formação de compostos insolúveis com o ferro, passando pelo trato intestinal sem ocorrer absorção (Reddy et al., 1996). 
Alimentos de origem vegetal, como os cereais e as leguminosas, contêm quantidades elevadas de ferro não-heme, porém, a biodisponibilidade é influenciada por diversos fatores dietéticos e fatores antinutricionais, tais como fitatos e taninos presentes nos alimentos, reduzindo substancialmente a disponibilidade de ferro na dieta, assim como o cálcio interfere na transferência de ferro heme e não heme através do mecanismo intracelular comum para ambos os elementos (Disler et al, 1975; Linder, 1988; Hallberg et al., 1992).

\subsubsection{Estimuladores da absorção de ferro não-heme}

Há grande quantidade de componentes nos alimentos capazes de formar quelato, atrair os minerais e transferi-los a um aceptor fisiológico molecular. Esses compostos são denominados "promotores ou intensificadores" (Clydesdale et al., 1991).

Como mencionado anteriormente, o elemento ferro se encontra na forma férrica ou ferrosa.

Os ferros férrico e ferroso são solúveis no $\mathrm{pH}$ do estômago, porém no $\mathrm{pH}$ intestinal ferro férrico precipita mais do que o ferro ferroso (Van Dokkum, 1992). Condições de óxido-redução podem influenciar na biodisponibilidade de vários elementos traço, assim como fatores dietéticos podem reduzir ferro férrico ao estado ferroso e aumentar a biodisponibilidade de ferro (Wise, 1995).

O ácido ascórbico é o promotor mais conhecido de ferro não-heme, aumentando absorção de ferro de várias fontes alimentares, conforme a quantidade na dieta (Monsen, 1982; Hallberg et al., 1986). O efeito desse ácido é melhorar a absorção de ferro, em primeiro lugar como agente redutor, pois converte o ferro férrico ao ferro ferroso, que é mais solúvel no $\mathrm{pH}$ do duodeno, prevenindo a formação de hidróxido férrico insolúvel, e, em segundo lugar, em condições altamente ácidas no estômago, formando complexos solúveis (quelatos) com íons férricos, mantendo essa solubilidade a $\mathrm{pH}$ alcalino no duodeno (Bothwell et al, 1989; Hallberg, 1981; Carpenter \& Mahoney, 1992).

Em adição ao ácido ascórbico, outros ácidos orgânicos dietéticos, incluindo ácido cítrico, ácido málico, ácido tartárico e ácido lático, aumentam a absorção de ferro (Bothwell et al., 1989). Além do mais, o efeito dos ácidos ascórbico e cítrico na absorção de ferro é 
aditivo, portanto há alta biodisponibilidade de ferro quando é suplementada com sucos e frutas cítricas (Ballot et al.,1987). Estudo “in vitro”, sugere que o ácido cítrico, ao invés do ácido ascórbico, pode ser o maior intensificador do ferro disponível em frutas e vegetais (Hazell \& Johnson, 1987).

Um efeito similar parece ter a vitamina $A$ e os $\beta$-carotenos. Esses compostos aumentam a absorção de ferro não-heme de diversos cereais, formando complexos solúveis com ferro, e prevenindo o efeito inibidor dos fitatos e polifénois na absorção do ferro (García-Casal et al, 1998).

\subsection{Anemia}

Na década de 70, no Brasil, os dados sobre a prevalência de anemia, embora restritos a estudos regionalizados, colocam-na como uma das mais sérias deficiências nutricionais (Sigulem et al., 1978).

A deficiência de ferro é uma desordem nutricional de alta prevalência mundial, contribuindo, significantemente, para redução da capacidade de trabalho, bem como para o aumento da morbidade e da mortalidade, afetando mais de 2 milhões de pessoas no mundo, as quais têm o feijão como alimento básico (Chaud \& Freitas, 1994; Della Penna, 1999).

O diagnóstico da anemia é feito a partir da determinação da concentração de hemoglobina no sangue (Yip, 1994).

A Organização Mundial de Saúde -OMS (1975) caracteriza a anemia para mulheres e crianças de 6 a 14 anos, quando a taxa de hemoglobina $(\mathrm{Hb})$ se apresenta inferior a 12 $\mathrm{g} / \mathrm{dl}$.

Anemia consiste na redução da concentração de hemoglobina circulante, desencadeada por diversos mecanismos fisiopatológicos tendo, entre outras consequiências, oxigenação tecidual ineficiente (De Vizia et al., 1985; Guyton, 1989; Oliveira, 1990).

Deve ser estabelecido, então, se a deficiência é devido à ingestão inadequada de ferro (deficiência de ferro primária) ou ao aumento de ferro secundário exigido para várias condições fisiológicas e/ou patológicas (Hambraeus, 1999).

A deficiência primária pode ocorrer devido não somente à quantidade ingerida inadequada, mas também a uma dieta de baixa biodisponibilidade e qualidade; ambos os 
casos representam, tanto quantitativa como qualitativamente, deficiência primária de ferro (Hambraeus, 1999).

A deficiência secundária de ferro pode ser relatada por variáveis fisiológicas, tais como o aumento do volume sangüíneo secundário, aumento de massa muscular devido a treinamento físico rigoroso, perdas menstruais e gravidez freqüente, ou vários problemas clínicos, como o aumento de perdas sangüíneas secundárias por trauma cirúrgico, tumores e infestações parasitárias (Hambraeus, 1999).

Os grupos populacionais dos lactentes, das adolescentes grávidas,das mulheres em idade fértil, das crianças menores de 5 anos e dos adolescentes são os mais susceptíveis, e, quando aliados à ingestão de alimentos deficientes em ferro, contribuem para o desenvolvimento da deficiência desse mineral, além de considerar o crescimento e perda de sangue devido a infecções e infestações parasitárias ou, ainda, à combinação desses três fatores, salientando que esses grupos populacionais requerem maior quantidade de ferro para atender suas necessidades nutricionais (Guyton, 1989 ; Oliveira,1990).

Há dificuldade em suprir os requerimentos desse mineral somente com as dietas tradicionais de muitos países, especialmente aqueles em desenvolvimento, dentre os quais o Brasil está incluído (Passmore, 1986; Marques et al., 1998; Figueiredo \& Kerbauy, 1995).

Somados a esses fatores, podemos citar ainda aqueles vinculados à questão social: baixa escolaridade dos pais, falta de saneamento básico e baixa condição sócio-econômica (De Vizia et al., 1985; Passmore, 1986; Figueiredo \& Kerbauy, 1995). A anemia ferropriva está relacionada com a sensibilidade a infecções, podendo afetar o desenvolvimento e influenciar negativamente na capacitação para o trabalho, pela redução da disponibilidade de oxigênio nos tecidos, afetando o rendimento cardíaco e a eficiência da troca de oxigênio no músculo, uma vez que esse mineral é considerado essencial, participando de inúmeras e importantes funções metabólicas (síntese de hemoglobina e de DNA, transporte de elétrons para a respiração celular, além de outras reações enzimáticas vitais) (De Vizia et al., 1985; Passmore, 1986). Sendo assim, o ferro torna-se essencial sob os aspectos nutricional e fisiológico, necessitando conhecer sua total biodisponibilidade no organismo humano.

Os alimentos naturalmente ricos em ferro e os enriquecidos com esse mineral são, sem dúvida, importantes elementos na prevenção da anemia ferropriva (Bianchi et al., 1992). 


\subsection{Fontes alimentares de ferro}

A determinação de ferro em alimentos é importante devido à necessidade da estimativa de seu teor para fins nutricionais.

As principais fontes de origem animal são as carnes vermelhas e as vísceras, em especial o fígado ( 8 a $10 \mathrm{mg} / 100 \mathrm{~g}$ ), e os moluscos bivalves $(7,7$ a $26 \mathrm{mg} / 100 \mathrm{~g})$. Entre as fontes de origem vegetal, as leguminosas secas $(5,5$ a $8,5 \mathrm{mg} / 100 \mathrm{~g})$ contêm quantidades elevadas (Martinez et al., 1999).

Os vegetais são a base da dieta da maior parte da população mundial. Esta apresenta baixa biodisponibilidade de ferro, quando comparada com dietas que contêm carne (Martinez et al., 1999).

A concentração de hemoglobina nos vegetarianos se encontra dentro dos níveis normais (Anderson et al., 1981).

\subsection{Medida da disponibilidade de ferro nos alimentos}

A aferição da ingestão de ferro, a partir da presença desse nutriente na composição dos alimentos, possui valor limitado como informação sobre o valor nutritivo da dieta, pois não indica a biodisponibilidade de ferro. O método "in vitro" baseia-se em medir o ferro que está disponível para absorção, através da digestão simulada do alimento ou dieta, mediante a determinação de ferro dialisável, utilizando membrana de diálise em equilíbrio (Miller et al., 1981) e mediante a diálise em fluxo contínuo (Minihane et al., 1993). Esses métodos não levam em consideração os fatores fisiológicos que afetam a eficiência na absorção do ferro, tais como o estado nutricional, transporte ativo, interações com a mucosa e flora intestinal, embora sejam importantes para obtenção de dados "in vivo" e permitam melhor controle das variáveis experimentais. Têm a vantagem de ser menos onerosos e de requerer menos cuidados que as técnicas “in vivo” (Fairweather-Tait et al., 1995).

Os fatores promotores e inibidores da absorção de ferro têm mostrado responder "in vitro" do mesmo modo como eles afetam a absorção de ferro “in vivo” (Hazell \& Johnson, 1987). 


\subsection{Propriedades nutricionais do feijão}

O feijão presente na dieta brasileira apresenta grande importância em relação ao valor nutricional. Além da alta quantidade de proteína, contribui como melhor fonte vegetal de ferro, sendo valiosa a sua contribuição em casos de deficiências. Porém, a quantidade total de ferro no alimento não indica a quantidade que será biodisponível. Há necessidade não só de quantificar o ferro como também de distinguir, no alimento, o ferro total do ferro biodisponível.

Feijão comum (Phaseolus vulgaris) é a leguminosa mais importante para a população mundial, principalmente, América Latina, Índia e África, nos quais a proteína animal é limitada por razões econômicas, religiosas e culturais. É uma leguminosa originária das regiões elevadas da América Central (México, Guatemala e Costa Rica), apresenta alto teor protéico na composição centesimal, é excelente fonte de carboidrato e fibra, apresenta baixo teor de lipídeos, sódio e não contém colesterol, além de possuir vitaminas (principalmente do complexo B) e minerais (Bressani \& Elías, 1974; Antunes \& Sgarbieri, 1980; Roston, 1990; Geil \& Anderson, 1994). Leguminosas são consideradas boas fontes dietéticas de ferro (Martínez et al., 1999).

No Brasil é a principal leguminosa fornecedora de proteínas, fazendo parte da dieta diária das classes sócio-econômicas de menor renda (Antunes et al,1995).

Aykroid \& Doughty (1982) descreveram como os feijões podem ser identificados, tais como, dry, kidney, haricot, pinto, comum, frijoles, chumbinho, opoca, rajma dhal.

$\mathrm{Na}$ década de 60, Pant \& Tulsiani (1969), pesquisando dezenove leguminosas silvestres, encontraram variação protéica de $18 \%$ a $47 \%$ entre os cultivares. Na década de 70, Silva \& Iachan (1975) realizaram pesquisas com dezessete cultivares brasileiros de feijão, encontrando variação protéica entre $22 \%$ a $32 \%$ de acordo com Tobin \& Carpenter (1978), os quais compilaram dados sobre a composição centesimal de feijões Phaseolus vulgaris, encontrando teores significativos de proteína, 26\%. Maldonado \& Sammám (2000) verificaram uma variação protéica de 25,1\% a 30, 2\% em cultivares de Phaseolus vulgaris.

O feijão é deficiente em aminoácidos sulfurados e rico em lisina, e o arroz é deficiente em lisina e relativamente rico em aminoácidos sulfurados, sendo considerados 
complementares. Devido a esse fato, é importante o papel desempenhado pelas misturas de cereais e grãos de leguminosas nos séculos de evolução da humanidade. O milho e o feijão, importantes ingredientes na dieta dos índios pré-colombianos, ainda hoje constituem alimentos básicos em certas regiões da América Latina. No Brasil, o arroz e o feijão são a base alimentar da população, melhorando o valor biológico das proteínas (Vieira, 1992).

Devido a sua composição, o feijão proporciona vários benefícios à saúde, sendo indicado na prevenção e no tratamento de várias doenças, tais como: distúrbios cardíacos, diabetes mellitus, obesidade e câncer, preenchendo as principais recomendações dietéticas para a boa saúde: aumento do consumo de fibras, amido e outros carboidratos complexos, e diminuição no consumo de lipídios e sódio. As principais instituições internacionais de incentivo e promoção à saúde indicam a ingestão diária de uma ou mais porções de feijão (Sathe et al., 1984; Geil \& Anderson, 1994).

Sammám et al. (1999) determinaram a concentração de proteína, umidade e cinza em condições que envolvessem o meio ambiente e condições do solo de vários cultivares de feijões no Noroeste da Argentina. O cultivar, local de crescimento, composição do solo, clima e tratamento com fertilizantes, alteram a composição de nutrientes. Os minerais e componentes antinutricionais das leguminosas variam, dependendo dos fatores ambientais.

Guzmám-Maldonado et al. (2000) determinaram os teores de proteína, aminoácidos, cálcio, ferro e zinco, além de taninos e ácido fítico de variedades silvestres de feijão comum (Phaseolus vulgaris L.) em dois estados do México em comparação com dois cultivares de feijão comum. Os feijões silvestres contêm mais proteína e maior digestibilidade protéica, quando comparados com feijões cultivados. Algumas amostras silvestres mostraram maiores teores de cálcio, ferro e zinco.

Canniatti-Brazaca \& Silva (1999) encontraram variação de 6,83 a 15,34 mg/100g de ferro nas leguminosas feijão preto, feijão comum, feijão branco, grão de bico, soja, feijão guandu e lentilha.

Martínez et al. (1998) avaliaram o efeito da variedade e tamanho da vagem de feijões verdes Phaseolus vulgaris quanto à composiçcão química, digestibilidade protéica, fatores antinutricionais e disponibildade dos minerais, concluindo que os feijões com tamanho da vagem menor possuem maior quantidade de minerais e lipídeos e baixo teor dos fatores antinutricionais. 
Sgarbieri et al. (1979) verificaram a composição e propriedades nutricionais de quatro variedades de feijões (Phaseolus vulgaris) cultivados e consumidos em grande quantidade no Brasil como rico-23, rosinha G2, carioca e piratã-1, encontrando que a disponibilidade do ferro foi de $45 \%$ para todas essas variedades, em relação ao teor do ferro total.

Elpo et al. (1998) determinaram os teores de ferro nos alimentos da cesta básica adquirida no comércio de Curitiba, Estado do Paraná, obtendo-se o teor de 8,03 mg/100g para o feijão cru.

\subsection{Fatores antinutricionais presentes nas leguminosas}

A presença de fatores antinutricionais proteícos e não-protéicos reduzem a qualidade nutricional do feijão.

Segundo Chubb ${ }^{1}$ citado por Canniatti-Brazaca (1997), podemos classificar os antinutricionais com base no tipo de nutriente que afeta como também pelo tipo de resposta biológica produzida no animal. Existem 3 grupos:

1) substâncias que prejudicam a digestibilidade ou a utilização metabólica das proteínas. São os inibidores de enzimas digestivas, as lectinas (hemaglutininas), as saponinas e os compostos fenólicos;

2) substâncias que reduzem a solubilidade ou interferem na utilização de elementos minerais: ácido fítico, ácido oxálico, glicosinolatos, gossipol;

3) substâncias que inativam ou aumentam os requerimentos de certas vitaminas. Antivitaminas lipossolúveis A, D, E e $\mathrm{K}$ e antivitaminas hidrossolúveis: tiamina, ácido nicotínico, piridoxina e cianocobalamina.

Os antinutricionais que fazem parte do alimento são de natureza variada. Há diversidade de natureza química, e existe diferença no conhecimento a respeito de sua natureza físico-química e dos seus mecanismos de ação fisiológica. Exercem ação tóxica ou antinutricional, quando ingeridos em sua forma ou estrutura nativa (alimentos crus ou insuficientemente cozidos) (Canniatti-Brazaca, 1997).

\footnotetext{
${ }^{1}$ Chubb, L.G. Antinutritive factors in animal feedstuffs. In: HARESING, W. Studies in the agricultural and food sciences butterwoths. Recent advances in animal nutrition, p. 21-37, 1982.
} 
Feijões comuns (Phaseolus vulgaris) e outras leguminosas contêm quantidades variáveis de compostos fenólicos, tais como taninos, encontrados principalmente na casca das sementes, constituindo fatores que têm sido sugeridos como responsáveis pela baixa biodisponibilidade de ferro em feijões, diminuindo o valor nutricional das leguminosas (Ummadi et al., 1995). O nível desses taninos está relacionado com a cor da semente: o branco possui quantidades muito baixas, enquanto o vermelho e o preto têm teores significantemente maiores (Bressani et al., 1983). Nos feijões crus encontram-se também outros antinutricionais como os fitatos, inibidores das enzimas proteases e lectinas (MartinCabrejas et al., 1997).

Antunes et al. (1995) verificaram a importância do valor nutricional e os fatores antinutricionais em quatro cultivares de feijão rico-23, rosinha G-2, carioca e piratã-1, concluindo que os fatores antinutricionais (antitripsina e lectina) dos feijões são altamente tóxicos, provocando letalidade nos ratos, quando administrados crus; a cocção, no entanto, aumenta a digestibilidade, tanto "in vitro" como "in vivo".

Comparando-se as variedades de feijão comum e feijão anasazi, verificourse que há diferença significativa na quantidade de taninos e lectinas, não havendo, porém, diferença quanto aos teores de estaquiose, rafinose, verbascose e inibidores de tripsina e quimotripsina (Weder et al., 1997).

\subsection{Alteração nos nutrientes do feijão com a manipulação e/ou processamento}

$\mathrm{O}$ tratamento térmico sobre as leguminosas inativa enzimas e melhora o sabor e aroma além do aumento no valor nutricional (Aykroid \& Doughty, 1982).

Segundo Canniatti-Brazaca (1997), a ação do calor destrói total ou parcialmente a ação tóxica de algumas substâncias antinutricionais.

Os feijões no estado maduro, logo após a colheita, apresentam cerca de $20 \%$ de umidade, sendo normalmente secos no campo até $10 \%$ de umidade e armazenados sob condições ambientais. O preparo dos feijões, para atingir as condições de consumo, engloba a maceração e cocção. Essas formas de processamento levam à inativação quase total dos fatores antinutricionais, aumento da digestibilidade, desenvolvimento de características de 
palatabilidade desejáveis com amolecimento da casca e dos cotilédones (Stanley \& Aguilera, 1985).

Canniatti- Brazaca (1994) testou três métodos de cocção quanto ao valor protéico de feijão guandu, sendo mais efetivo o que embebia os grãos em água destilada por 16 horas na proporção de 1:3, sendo desprezada a água e colocada novamente água destilada na proporção de $1: 2$ e autoclavados por 10 minutos em temperatura a $121^{\circ} \mathrm{C}$.

Candela et al. (1997) avaliaram o efeito da cocção realizada por uma companhia de fornecimento de refeições quanto ao valor nutricional de feijão comum, grão-de-bico e lentilhas, sendo verificada mudança na composição após cocção. Essas leguminosas são importantes componentes das dietas, como a dieta do Mediterrâneo e são excelentes fontes de proteínas e carboidratos.

Herrera et al. (1998) analisaram o conteúdo de fibra dietética total (FDT), fibra dietética insolúvel (FDI) e fibra dietética solúvel (FDS) em vinte e seis leguminosas, encontrando para FDT os valores de $13,6 \%$ a 28,9\% para leguminosas cruas e de 16,1\% a $27 \%$ para as leguminosas processadas. Os valores de FDI em todas leguminosas foram maiores que FDS.

Gonzáles (2000) notou que os tratamentos térmicos podem ter efeitos variáveis na fibra dietética e que a cocção promove o rompimento dos componentes celulares do feijão (celulose, hemicelulose, lignina, pectina e gomas), além de propiciar interações entre proteínas e lipídeos, assim como trocas qualitativas e quantitativas que variam na composição total da fibra dietética ao comparar alimento cru e cozido. Há controvérsias entre pesquisadores, constatando que a cocção ora aumenta, ora diminui o teor de fibra dietética .

O processo de extrusão é reconhecido como um processo capaz de reduzir a concentração de fatores antinutricionais em produtos alimentares. Esse processo pode ser considerado uma boa alternativa para produção de novos alimentos frnecedores de ferro ou mesmo alimentos fortificados de ferro (Poltronieri et al., 2000).

A presença de fatores antinutricionais em feijão, tais como, inibidor de tripsina, lectina, ácido fítico e taninos reduz seu valor biológico. Os métodos de processamento alimentar melhoram o valor nutricional de leguminosas, porém esses não podem ser aplicados em feijões endurecidos. O processo de estado de fermentação sólida (SSF) 
melhora o valor nutricional e sensorial de enorme variedade de leguminosas (Sathe \& Salunkhe, 1984; Parede-Lopes \& Harry, 1988).

Parede-Lopes \& Harry (1989) avaliaram o desenvolvimento do produto fermentado tempeh no qual utilizou feijão comum cru e endurecido (HTC), e o efeito da fermentação em vários fatores químicos e antinutricionais, ocorrendo alterações químicas, como aumento da quantidade de proteínas e carboidratos solúveis em 72 horas de fermentação, diminuição da quantidade de lipídeos, fibra, e antinutricionais (lectina, taninos e ácido fítico).

A autoclavagem de três tipos de leguminosas, feijão guandu, feijão caupi e soja demonstrou que sempre o grão autoclavado foi superior ao cru em suas qualidades nutricionais (Nwokolo \& Oji², citados por Canniatti-Brazaca (1997)).

Amaya et al. (1991) avaliaram o efeito da recocção no feijão submetido a 3 horas de cocção sob pressão $\left(96^{\circ} \mathrm{C}\right)$ e recocção por 15 minutos depois de 12,24 e 36 horas, da primeira cocção, obtendo amostras de feijão cozido sem caldo, com caldo e do caldo. Os autores concluíram que o efeito da recocção sobre a qualidade da proteína foi positiva, principalmente sobre sua digestibilidade, porém a quantidade da proteína não foi alterada. A disponibilidade do ferro em feijão cozido e no caldo é baixa. O processo de recocção após 12 horas apresentou a melhor disponibilidade de ferro, principalmente no caldo.

Goycoolea et al. (1990) verificaram a relação entre diversos métodos de preparação do feijão, o valor nutritivo de sua proteína e a presença de taninos no feijão (Phaseolus vulgaris L.). Foram detectadas altas concentrações de taninos nos caldos de cocção em diferentes modalidades de preparações caseiras. O tempo de cozimento prolongado teve efeito prejudicial sobre a qualidade da proteína. Tanto a maceração como cocção tiveram papéis importantes como alternativa da eliminação de taninos presentes na dieta.

O tempo necessário para maceração e cocção varia pelos cultivares e espécies dos feijões (Aykroid \& Doughty, 1982).

Bressani et al. (1982) concluíram que a fração de taninos não se liga à proteína, e sim se deposita em grande parte no caldo de cozimento, enquanto Goycoolea et al. (1990) reportaram que há relação inversa entre tempo de cocção e o conteúdo de taninos residuais

${ }^{2}$ NWOKOLO, E.; OJI, U.I. Variation in metabolizable energy content of raw or autoclaved white and brown varieties of theree tropical grain legumes. Animal Feed Science and Technology, v. 13, n. 1-2, 141-146, 1985. 
no caldo, tanto cocção em panela normal como de pressão. Esse fato pode estar associado à formação de complexos moleculares entre taninos e compostos que vão se depositando no caldo ao longo da cocção (proteína, lipídeos, oligossacarídeos). Os taninos se localizam na casca da semente, ligam-se às proteínas, formando um complexo hidrofóbico insolúvel e não digerível pelo organismo. Tanto o remolho como a cocção têm papel importante como alternativa da eliminação por parte dos taninos presentes na dieta.

O processo de germinação diminui a quantidade de antinutricionais. A germinação durante 5 dias diminuiu os teores de inibidores de tripsina, quimotripsina, alfa-amilase e ácido fítico (Sathe et al., 1983). Etapas do processamento envolvendo maceração, moagem, cozimento, fermentação, autoclavagem, assim como a germinação, podem reduzir ou destruir quantidades apreciáveis de ácido fítico em cereias e leguminosas (Reddy et al., 1982).

Segundo Sathe et al. (1983), o ácido fítico foi destacado por ser um dos fatores responsáveis pela redução da biodisponibilidade de minerais, porém, em relação à germinação, ocorre aumento da qualidade nutricional.

Ene-Obong (1995) verificou os níveis de antinutricionais nos cultivares da África yambean (Sphenostylis stenocarpa), feijão guandu (Cajanus cajan) e feijão de corda (Vigna unguiculata) na Nigéria. Concluiu que os antinutricionais (tripsina, fitato e tanino) podem ser eliminados ou reduzidos durante maceração, descascamento, fermentação e germinação, lembrando que o problema da digestibilidade da proteína vegetal tem sido questionada sobre os efeitos de vários fatores como fitato, taninos, lectinas entre outros.

Ologhobo \& Fetuga (1984) analisaram os efeitos de remolho, germinação, cocção e autoclavagem quanto aos teores de hemaglutinina, taninos, ácido fítico, inibidores de tripsina em dez variedades de caupi (Vigna unguiculata (L.) Walp) cultivadas na Nigéria. Os resultados indicaram que a germinação e remolho foram os tratamentos mais efetivos para diminuição de fitatos, enquanto a germinação e cocção foram os mais efetivos para taninos, confirmando que os métodos tradicionais de cocção são adequados em eliminar algumas das substâncias indesejáveis.

Desphande et al. (1982) verificaram os teores de taninos e fitatos em 10 cultivares do feijão Phaseolus vulgaris nos grãos inteiros e descascados; em relação aos teores de taninos ocorreu variação de 33,7 a 282,8 mg Eqcatequina/ 100g de feijão e 10,0 a 28,7 mg 
Eqcatequina/ 100g de feijão para grãos inteiros e descascados, respectivamente, observando diminuição nos teores em grãos descascados; porém, ocorreu o inverso para fitatos, sendo a variação de 11,6 a 29,3 mg/g e 16,3 a 36,7 mg/g para grãos inteiros e descascados, respectivamente.

Ene-Obong \& Obizoba (1996) avaliaram os efeitos dos processamentos (remolho, descascamento, fermentação e tratamento térmico) no tempo de cocção, proteína, minerais, taninos, fitato e digestibilidade protéica "in vitro" do Sphenostylis stenocarpa, sendo o tratamento em maceração por 12 horas o mais apropriado para reduzir níveis de taninos, fitatos e tempo de cocção, porém houve decréscimo na quantidade de ferro.

A fração da cinza, praticamente não é alterada com processamento, assim, os minerais provavelmente não são afetados com o processamento dos alimentos. O máximo de perdas minerais ocorre durante a cocção podendo chegar a 3\% (Karmas \& Harris, 1988).

Embora os minerais possam não ser perdidos durante o processamento, a combinação com outros nutrientes ou componentes alimentares pode tornar o mineral não disponível para absorção, portanto, o efeito oposto também pode ocorrer, ou seja, o aumento da biodisponibilidade por causa da destruição de ligantes (Karmas \& Harris, 1988).

\subsection{Irradiação de alimentos}

Devido à importância do feijão comum e a essencialidade do ferro sob o aspecto nutricional e fisiológico, é necessário determinar a disponibilidade, além de avaliar as alterações nos antinutrientes causadas pela irradiação, o que influenciará na biodisponibilidade de ferro no organismo humano.

Alimentos irradiados são alimentos que foram tratados por um determinado tipo de radiação, em condições de segurança controladas, para obtenção de algumas propriedades convenientes, tais como inibir brotamento ou destruir bactéria, entre outras, além de manter a boa qualidade do alimento por mais tempo (IAEA, 1992).

Feijões secos de Phaseolus vulgaris são importantes fontes de alimentos especialmente nos países em desenvolvimento, onde estes são a maior fonte dietética de proteína. Em países tropicais, a estocagem de feijão comum em alta temperatura, alta 
umidade relativa do meio e tempo de armazenamento prolongado torna-os susceptíveis ao fenômeno de endurecimento e à maior infestação de insetos, além de mudanças indesejáveis na textura e sabor, degradação de fitatos e metionina, aumentando o tempo de cocção (Martin- Cabrejas et al., 1997). A irradiação poderia reduzir essas perdas, portanto manter a qualidade nutricional desses feijões (Delincée et al., 1998). Maior vida útil e melhoramento da qualidade tecnológica são apontados para o processamento de alimentos irradiados (Ahmed, 1993).

Cunha et al. (1993) verificaram os efeitos dos tratamentos com radiação gama, utilizando dose de $2 \mathrm{kGy}$ de fonte $\mathrm{Co}^{60}$ e cocção em forno de microondas até 2 minutos, sobre as propriedades físico-químicas e sensoriais de feijões secos durante 6 meses de estocagem sob refrigeração $\left(4^{\circ} \mathrm{C}-5^{\circ} \mathrm{C}\right)$ e a $30^{\circ} \mathrm{C}$, com $75 \%$ de umidade relativa. Em relação à textura e ao sabor, a irradiação prolongou a vida dos feijões secos estocados a $30^{\circ} \mathrm{C}$, sendo esta a condição comumente encontrada em países tropicais onde feijões secos são alimentos básicos importantes, embora as radiações ionizantes possam provocar o amolecimento de grãos de leguminosas.

Mancini-Filho (1990) observou reduções iguais ou superiores a 50\% no tempo de cocção de feijões (Phaseolus vulgaris L.) das variedades catu e rajado armazenados por 9 e 12 meses, irradiados com doses de $10 \mathrm{kGy}$.

Segundo Pinn (1992), os feijões (Phaseolus vulgaris L.) irradiados com doses de 10 kGy apresentaram redução no tempo de cocção de aproximadamente 64\% em relação ao controle (53 minutos), equivalendo a 19 minutos.

A irradiação de alimentos é um tratamento que consiste em submeter os alimentos, já embalados ou a granel, a uma quantidade minuciosamente controlada de radiação ionizante, por um tempo prefixado, com objetivos bem determinados. O processo não aumenta o nível de radioatividade normal dos alimentos. Poderão ser utilizadas, em geral nos alimentos as irradiações ionizantes, cuja energia seja inferior ao limiar das reações nucleares que poderiam induzir radioatividade no material irradiado. A irradiação pode impedir a divisão de células vivas, tais com bactérias e células de organismos superiores, ao alterar suas estruturas moleculares, além de retardar a maturação de algumas frutas e legumes, ao produzir reações bioquímicas nos processos fisiológicos dos tecidos vegetais (IAEA, 1992; Diehl, 1995). 
O emprego das radiações ionizantes gama e feixe de elétrons, na preservação de alimentos, está crescendo mundialmente. A grande diferença entre os raios gama provenientes de uma fonte de ${ }^{60} \mathrm{Co}$ e os elétrons oriundos de um acelerador industrial é o seu poder de penetração (Hayashi, 1991). A radiação gama tem um grande poder de penetração, mas é de baixa intensidade, e o feixe de elétrons gerado por um acelerador tem um poder de penetração menor, mas alta taxa de dose de radiação (Diehl, 1995). Nem todos os tipos de radiação são apropriados para a irradiação de alimentos, assim sendo a FAO/OIEA/OMS publicou as normas gerais do Codex para alimentos irradiados (FAO, 1983; Diehl,1995).

Nos processos industriais por irradiação, é fundamental que se conheça a quantidade de energia absorvida pelo material, quando ele é exposto à radiação ionizante. A dose absorvida, ou simplesmente dose, é a quantidade de energia absorvida. A unidade que mede a dose absorvida é o gray (Gy), 1 Gy eqüivale a $1 \mathrm{~J}$ (Joule) de energia absorvida por $1 \mathrm{Kg}$ de alimento irradiado. A taxa de dose é a energia absorvida por unidade de tempo, assim, os irradiadores gama diferem dos aceleradores por possuírem uma baixa taxa de dose, levando mais tempo de irradiação, enquanto os aceleradores, com sua alta taxa de dose, podem ser muito mais rápidos (Diehl, 1995).

É importante salientar que tanto a radiação gama de ${ }^{60} \mathrm{Co}$, como a dos feixes de elétrons dos aceleradores, não têm energia suficiente para provocar qualquer reação nuclear na matéria e, portanto, não deixam nenhum resíduo radioativo no material após a irradiação (IAEA, 1992; Diehl, 1995).

Segundo Villavicencio (1998, 2000), o tratamento por radiação nas doses de 0; 0,5; 1; 2,5; 5; $10 \mathrm{kGy}$ afetou o teor de taninos e fitatos em feijão comum e caupi, ocasionando decréscimo nos teores de taninos e fitatos (somente na fração inositol hexafosfato), conforme o aumento da dose de radiação. 


\section{MATERIAL E MÉTODOS}

O experimento foi desenvolvido no Laboratório de Bromatologia do Departamento de Agroindústria, Alimentos e Nutrição da Escola Superior de Agricultura "Luiz de Queiroz"/ USP.

\subsection{Matéria prima}

A matéria prima, utilizada para a realização das análises em grãos crus e cozidos de Phaseolus vulgaris L. variedade carioca, foi adquirida no Mercado Municipal de Piracicaba- SP. Os grãos foram irradiados, utilizando raios gama, provenientes do irradiador de Cobalto $^{60}$, comercial para alimentos, modelo JS - 8.900, da Nordion, com atividade de $1.200 .000 \mathrm{Ci}$, nas doses de 0, 2, 6 e $10 \mathrm{kGy}$, pela CBE (Companhia Brasileira de Esterilização), sediada no município de Jarinu-SP. A quantidade de dose absorvida durante a irradiação foi medida através de dosímetro polimethilmetacrildo (PMMA- Red perspex). A leitura foi realizada em espectrofotômetro, e a dose de radiação absorvida foi relatada quantitativamente no intervalo de $530 \mathrm{~nm}$.

\subsection{Análises químicas}

\subsubsection{Preparo das amostras}

As amostras foram analisadas quanto à composição centesimal e separadas em porções de $500 \mathrm{~g}$, em sacos de polietileno, e submetidas às doses de radiação de 0,2 , 6 e 10 kGy. 
Os grãos crus foram triturados em moinhos de facas, peneirados em malha de 30 "mesh", obtendo-se assim a farinha a ser utilizada para análises químicas. Essa farinha foi armazenada em saco de polietileno, fechado, e mantida em temperatura de refrigeração $\left(4^{\circ} \mathrm{C}\right)$.

Os grãos para cocção foram colocados em maceração em água destilada na proporção de 1:3; após 16 horas de maceração, á água foi desprezada e colocada água destilada na proporção de $1: 2$ por 10 minutos a $121^{\circ} \mathrm{C}$ para cocção, em autoclave, conforme a metodologia sugerida por Molina et al. (1975). Após o cozimento, as amostras foram colocadas em bandejas de alumínio e secas em estufa de circulação de ar forçada à temperatura de $50-55^{\circ} \mathrm{C}$ até peso constante (aproximadamente 24 horas). O material foi posteriormente moído e armazenado, conforme descrito para os grãos crus. Todas as análises foram realizadas em triplicata.

\subsubsection{Composição centesimal}

As análises químicas de teor de umidade, proteína bruta, extrato etéreo e de cinza foram realizadas de acordo com a metodologia indicada pela AOAC (1995).

Para determinação do teor da matéria seca, foi utilizado o método gravimétrico em que as amostras foram secas em estufa a $105^{\circ} \mathrm{C}$, até peso constante.

O teor de nitrogênio total foi determinado pelo método Microkjeldahl, sendo o teor protéico determinado multiplicando-se o conteúdo de nitrogênio total pelo fator 6,25.

O extrato etéreo foi determinado, utilizando-se extrator de Sohxlet. Na extração foi utilizado, como solvente, éter etílico à temperatura de $45-50^{\circ} \mathrm{C}$ em refluxo contínuo da amostra por 6 horas. Recuperado o éter etílico, os tubos foram retidos e colocados em estufa por 20 minutos a $100^{\circ} \mathrm{C}$, deixando esfriar em dessecador e pesados, obtendo-se a quantidade de lipídeos por diferença do peso do tubo.

A cinza foi determinada incinerando a amostra em mufla à temperatura de 550 $600^{\circ} \mathrm{C}$ por 4 horas.

Os carboidratos foram obtidos por diferença $100 \%$ - (\% proteína $+\%$ umidade $+\%$ fibra $+\%$ cinza). 
O teor de fibra dietética foi determinado de acordo com o Total.....(2000). Esse ensaio determina o conteúdo de fibra total de alimentos usando uma combinação dos métodos enzimáticos e gravimétricos. As amostras de alimentos secos, livres de gordura (desengorduradas) foram gelatinizadas com $\alpha$ - amilase estável ao calor e então digeridas enzimaticamente com protease e amiloglicosidase para remoção da proteína e do amido existentes nas amostras. O etanol foi adicionado para precipitar a fibra solúvel. Esses resíduos foram então filtrados e lavados com etanol e acetona. Após secagem, os resíduos foram pesados. Metade das amostras foi analisada para proteína e a outra metade, queimada a cinza. O total de fibra é o peso do resíduo menos o peso da proteína e cinza.

\subsubsection{Minerais}

Os minerais foram determinados pelo método descrito por Sarruge e Haag (1974), sendo utilizada a digestão com ácido nítrico perclórico a $50^{\circ} \mathrm{C}$ por 10 a 15 minutos, a $100^{\circ} \mathrm{C}$ até digerir todo o material e atingir temperatura de $150^{\circ} \mathrm{C}$. Após resfriamento e diluição do material com água desmineralizada foi realizada a leitura em espectrofotômetro de absorção atômica modelo PERKIM-ELMER 360. Foram utilizados os seguintes comprimentos de ondas: 422,7 nm para cálcio; $324 \mathrm{~mm}$ para cobre, 248,3 $\mathrm{nm}$ para ferro, 285,2 nm para magnésio, 279,5 nm para manganês e 213,9 nm para zinco. O potássio e o fósforo foram determinados em espectrofotômetro colorimétrico com o comprimento de onda de $420 \mathrm{~nm}$.

\subsubsection{Fatores antinutricionais}

\subsubsection{Taninos}

Os taninos foram analisados segundo a metodologia descrita por Price et al. (1980), através da extração com metanol e reação colorimétrica com solução de vanilina a $1 \%$ em metanol $8 \%$ de $\mathrm{HCl}$ em metanol na proporção de $1: 1$, deixados a $30^{\circ} \mathrm{C}$ por 20 minutos e posterior leitura a 500nm. Para a construção da curva padrão foi utilizada catequina e os resultados foram expressos em $\% \mathrm{mEq}$ catequina. 


\subsubsection{2 Ácido fítico}

A quantidade de ácido fítico foi determinada segundo o método de Grynspan \& Cheryan (1989). A amostra foi colocada em solução digestora e posteriormente centrifugada, o sobrenadante diluído em água destilada foi passado por resina e algodão, e depois $\mathrm{NaCl}$. Ao eluído foi adicionado o reativo de Wande e, posteriormente, foi feita leitura em espectrofotômetro a $500 \mathrm{~nm}$. A quantidade de ácido fítico foi determinada segundo o método de Grynspan \& Cheryan (1989), com posterior leitura em espectrofotômetro a $500 \mathrm{~nm}$.

\subsubsection{Disponibilidade de ferro "in vitro"}

Foi realizada diálise, segundo método proposto por Luten et al.(1996). O feijão foi submetido a digestão "in vitro". Essa digestão foi realizada inicialmente com pepsina em $\mathrm{HCl}$ 0,1M (160 mg pepsina/ml) a pH 2, incubada a $37^{\circ} \mathrm{C}$ por 2 horas sob agitação e, posteriormente, adicionada solução de pancreatina-bile em carbonato de sódio $(25 \mathrm{mg} / \mathrm{ml})$ a $\mathrm{pH} 7,5$ a $37^{\circ} \mathrm{C}$ por 30 minutos. O material obtido foi colocado em saco de diálise e incubado mais 2 horas a $37^{\circ} \mathrm{C}$, depois foi lavado com água deionizada, sendo medido o ferro dialisado no conteúdo obtido com leitura a $533 \mathrm{~nm}$.

\subsection{Análise Estatística}

O delineamento estatístico foi inteiramente casualizado. Foi realizada análise de variância pelo teste $\mathrm{F}$, e a comparação das médias obtidas nos diferentes tratamentos foi analisada segundo teste de Tukey $(\mathrm{p}<0,05)$ (Pimentel - Gomes, 1982). 


\section{RESULTADOS E DISCUSSÃO}

Segundo Pinn (1992), com relação aos resultados referentes à composição centesimal dos feijões, irradiados da variedade carioca, não houve variação nos teores de umidade, cinza, proteína, extrato etéreo e carboidratos entre as diferentes doses de radiação.

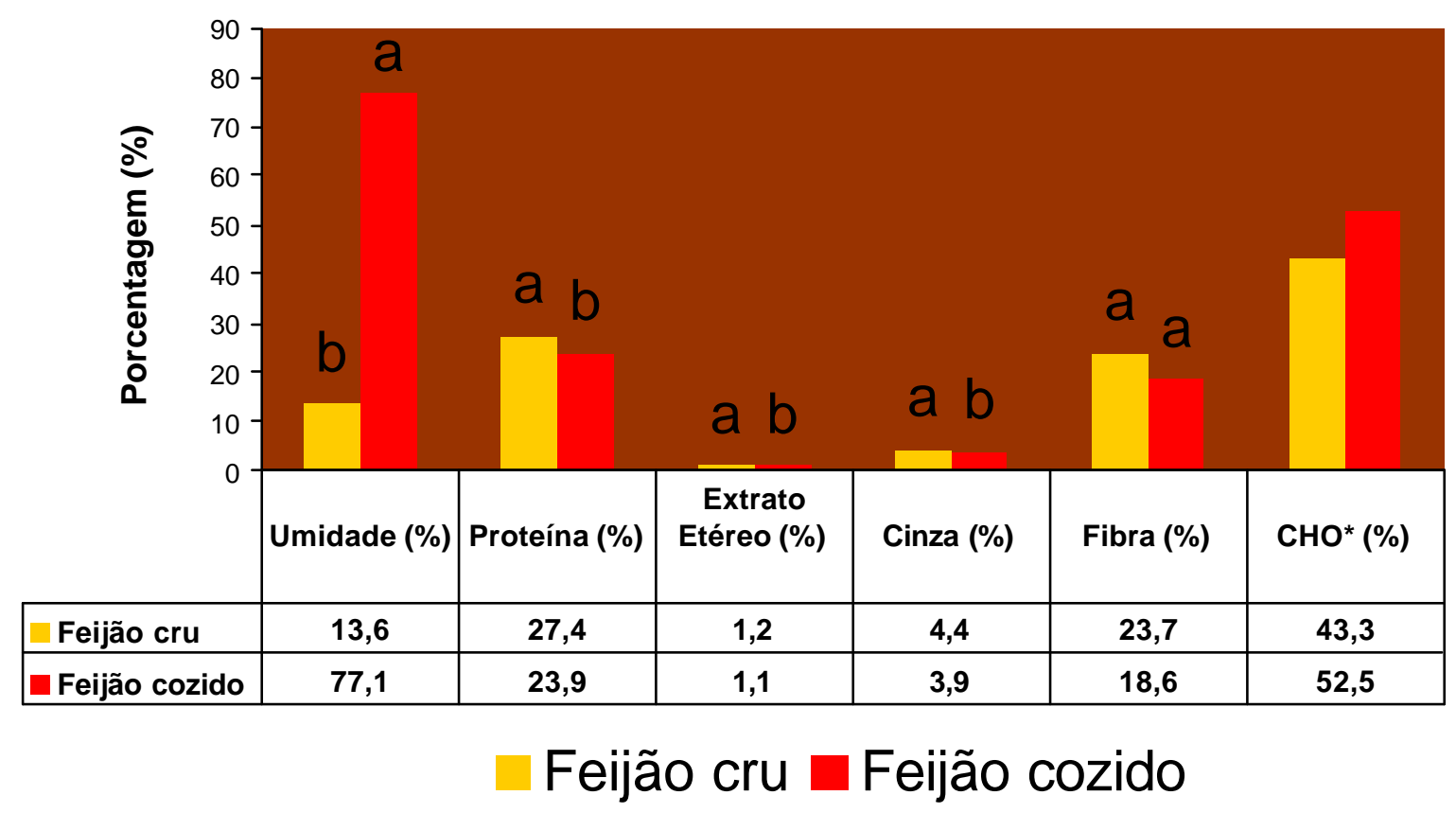

Figura 1 - Composição centesimal dos grãos de feijão cru e cozido (base seca) Letras diferentes nas colunas de mesma cor diferem significativamente entre si $(p \leq 0,05)$

A umidade do grão cru e cozido difere devido ao processo de maceração e cocção. Maldonado \& Sammám (2000) encontraram para o feijão carioca cru o valor de 13,27\%, valor semelhante ao encontrado por Weder et al. (1997), analisando feijão anasazi que contém 9,9\% de umidade. A média da umidade encontrada por Pinn (1982) na análise do 
feijão carioca cozido irradiado foi de 10\%. Herrera et al. (1998) obtiveram, para feijão carioca cru e cozido, os respectivos teores de umidade $12,3 \%$ e $12,1 \%$, sendo a amostra do feijão cozido desidratado antes da análise. O feijão cozido, segundo os dados da Tabela de composição de alimentos da Faculdade de Ciências Farmacêuticas (Universidade...., 2001) apresentou o teor de umidade $69,2 \%$. Os valores apresentados estão semelhantes aos obtidos neste trabalho.

O teor de proteína encontrado para feijão cru e cozido está de acordo com a média encontrada por Tobin \& Carpenter (1978), que foi de 26\%. Segundo Bressani \& Elías (1974), o conteúdo de proteínas de várias leguminosas varia de $18 \%$ a $32 \%$.

Candela et al. (1997) avaliaram feijão comum (Phaseolus vulgaris) cru e cozido quanto ao teor protéico e encontraram, respectivamente, 23,33\% e 28,16\%. Sammám et al. (1999) obtiveram, em matéria seca, para feijão carioca cru, o teor de 23,06\% confirmado por Maldonado \& Sammám (2000). Antunes et al. (1995) encontraram 23,37\%, em matéria seca, para feijão cru, sendo o mesmo valor verificado por Sgarbieri et al. (1979) para feijão cozido. Parede-Lopez \& Harry (1989), analisando o cultivar canário 10, obtiveram 23,8\% de proteína. A média de proteína encontrada por Pinn (1982) na análise do feijão carioca cozido irradiado foi de $22 \%$.

A quantidade de extrato etéreo certifica que o processo de maceração e cocção altera o valor de lipídeos. Os teores encontrados na literatura são, em média, 1,7\% no feijão cru, segundo Tobin \& Carpenter (1978). A média de extrato etéreo encontrada por Pinn (1982) na análise do feijão carioca cozido irradiado foi de 2\%. Maldonado \& Sammám (2000) encontraram no feijão cru a quantidade de $1,01 \%$ de extrato etéreo, valor confirmado por Sammám et al. (1999). Já Antunes et al. (1995) verificaram, no feijão carioca cru, 1,45\% de lipídeos, sendo esse o mesmo valor para feijão cozido verificado por Sgarbieri et al. (1979). Parede-Lopez \& Harry (1989) apresentaram para o feijão canário 10 cru 1,2\% de extrato etéreo. Candela et al. (1997) encontraram os seguintes valores para feijão comum (Phaseolus vulgaris), respectivamente, 3,50\% e 3,91\%. 
Os resultados da cinza são condizentes com os apresentados por Tobin \& Carpenter (1978), no qual o teor de cinza apresentou 4,11\%, e com a média encontrada por Pinn (1992) na análise do feijão carioca cozido irradiado de 4\%. O conteúdo de cinza em leguminosas varia de 2,5\% a 4,2\% na matéria seca (Bressani \& Elías, 1974). Também estando de acordo com Antunes et al. (1995), que analisaram os cultivares de feijão (Phaseolus vulgaris), entre eles, o cultivar carioca e encontraram o valor de 4,18\% para feijão cru, assim como Sgarbieri et al. (1979), que encontraram, para feijão cozido, o teor semelhante. Parede-Lopez \& Harry (1989) verificaram que o cultivar canário 10 apresentou $5 \%$ de cinza. Sammám et al. (1999) encontraram o teor de $4,45 \%$ no feijão carioca cru, de acordo com Maldonado \& Sammám (2000), equivalente ao resultado obtido na pesquisa. Candela et al. (1997), analisando feijão comum (Phaseolus vulgaris), obtiveram respectivamente, os seguintes teores no cru e cozido 4,87\% e 5,65\%, concluindo que a quantidade de elementos minerais com a aplicação do tratamento de maceração e em seguida térmico altera significantemente o valor, conforme encontrado nesta pesquisa.

Quanto ao teor de fibra dietética total (FDT), houve equivalência para o feijão cru, mas não para o feijão cozido, com os dados da Tabela de composição de alimentos da Faculdade de Ciências Farmacêuticas (2001), que apresenta a quantidade de 24,56\% para feijão cru, 25,87\%, para feijão carioca cozido, 22,15\% para feijão mulatinho cozido e $25,64 \%$ para feijão preto cozido.

Gonzáles (2000), analisando a quantidade de FDT para tratamentos térmicos distintos, encontrou, em relação ao calor prolongado, panela de pressão e feijão sem tratamento (cru), os valores de 21,24; 25,63 e 24,31\% respectivamente.

Herrera et al. (1998), em análise de FDT no feijão comum cru e cozido encontraram os teores de $30,8 \%$ e $26,4 \%$, respectivamente, sendo teores superiores aos encontrados nesta pesquisa, enquanto Aykroid \& Dougthy (1982) apresentam o teor de 28,9\% de FDT para feijão comum cru. A média de FDT encontrada por Pinn (1982) na análise do feijão carioca cozido irradiado foi de $26,87 \%$. 
Segundo Sammám et al. (1999), o feijão comum, variedade carioca, produzido em diferentes regiões do noroeste na Argentina, apresenta as seguintes médias para cobre $(\mathrm{Cu})$, ferro $(\mathrm{Fe})$, zinco $(\mathrm{Zn})$ e fósforo $(\mathrm{P})$ 1,12; 10,26; 3,44 e 339,74 mg/100g, respectivamente. Maldonado \& Sammám (2000), analisando minerais das variedades do feijão Phaseolus vulgaris, entre eles feijão comum carioca cru, encontraram os seguintes teores $\mathrm{Cu} 1,13 ; \mathrm{Fe}$ 10,27, Zn 3,44 e P 340,13 mg/100g, sendo semelhantes aos apresentados nas tabelas 1 e 2 .

Os teores de minerais encontrados nos feijões irradiados cozidos da variedade carioca não variaram, como esperado, em função das doses de radiação empregadas, de acordo com Pinn (1992), verificando que as concentrações de ferro, zinco, cobre, cálcio fósforo são, em média, iguais a 16,2; 2,8; 0,63; 56,4 e $362 \mathrm{mg} / 100 \mathrm{~g}$ de feijões, respectivamente.

Martínez et al. (1998) encontraram para as variedades em feijões verdes cozidos Cleo, Strike e Sentry Phaseolus vulgaris os seguintes teores quanto aos macrominerais: sódio 33,49 a 45,91; potássio 183 a 274; cálcio 546 a 711; magnésio 261 a $315 \mathrm{mg} / 100 \mathrm{~g}$; em relação aos microminerais, os teores de ferro 5,52 a 7,09; zinco 4,26 a 4,87; cobre 1,27 a 2,24 e manganês 1,84 a 2,71 $\mathrm{mg} / 100 \mathrm{~g}$.

Segundo Ene-Obong \& Obizoba (1996), os teores de cálcio, ferro, magnésio, fósforo e zinco apresentaram diminuição após o processo de cocção da leguminosa Sphenostylis stenocarpa, o mesmo ocorrendo para o feijão comum (tabelas 1 e 2). 
Em relação ao teor de taninos no feijão cru e cozido irradiados com $0,2,6$ e 10 $\mathrm{kGy}$, obtiveram-se valores apresentados na figura 2 .

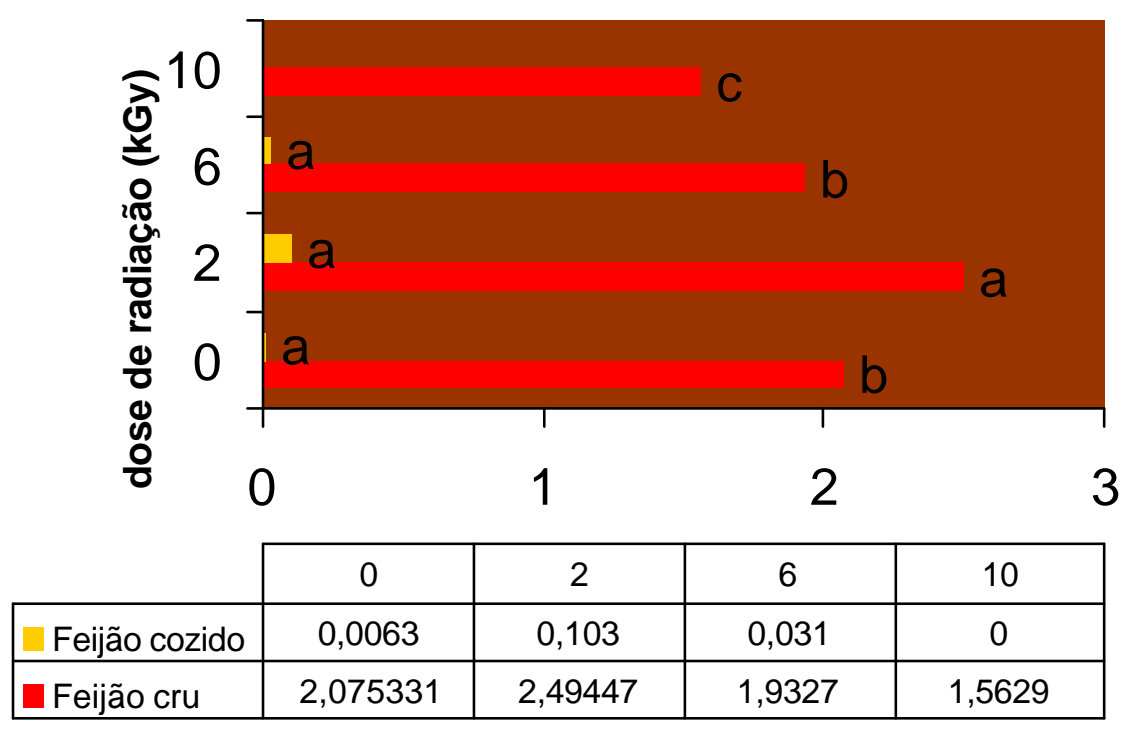

TANINOS (\%mEqcatequina)

\section{— Feijão cru Feijão cozido}

Figura 2 - Concentrações de taninos dos feijões irradiados da variedade carioca

Letras diferentes nas colunas de mesma cor diferem significativamente entre si $(p \leq 0,05)$

$\mathrm{Na}$ determinação de taninos utilizou-se a catequina como padrão. Alguns autores (Bressani et al., 1983) utilizam o ácido tânico para essa finalidade. Tendo em vista a presença de catequina nos feijões, torna-se mais adequado utilizá-la como padrão.

Comparando-se com o conteúdo de taninos, segundo Villavicencio et al. (2000), que obtiveram o valor de $0,18 \% \mathrm{mEq}$ catequina em matéria seca em feijão cru não irradiado (0 kGy) e para as doses de 2,5; 5 e 10 kGy em feijão cru obtiveram os valores de 0,16; 0,14 e $0,14 \% \mathrm{mEq}$ catequina e para o feijão cozido os teores de 0,$15 ; 0,13$ e $0,10 \% \mathrm{mEq}$ catequina, respectivamente, verificando que, embora os valores sejam diferentes, em ambos os estudos o conteúdo de taninos diminuiu com o aumento da dose de radiação em feijão cru, assim como cozido, com exceção da dose de $2 \mathrm{kGy}$, na qual ocorreu aumento da quantidade de taninos. 
Pinn (1992), utilizando feijão cozido (Phaseolus vulgaris L.) variedade carioca irradiados nas doses de 2; 4; 6; 8; 10; 15 e 20 kGy, verificou diminuição no teor de taninos conforme aumento da dose de radiação; o teor de taninos controle apresentou 0,47 \% mEq catequina e com a dose de radiação $20 \mathrm{kGy}$ o teor apresentado foi de $0,29 \% \mathrm{mEq}$ catequina.

Desphande et al. (1982) reportaram que o conteúdo de taninos em diferentes variedades de feijões variaram de 33,7 a 282,8 mg Eqcatequina/ 100g.

Ologhobo \& Fetuga (1984) utilizando 10 variedades de feijão de corda Vigna unguiculata L.) Walp cozidos em panela de pressão, por 15 minutos ou autoclavadas a $105^{\circ} \mathrm{C}$ por 20 minutos, encontraram redução na quantidade de taninos, em média, de 42,8 \% e $20,7 \%$ respectivamente, como ocorreu, na presente pesquisa, a diminuição dos taninos com a cocção, de acordo com Goycoolea et al. (1990), no qual tratamento térmico produz redução de 80 a $90 \%$ na quantidade de taninos.

Já Ene-Obong \& Obizoba (1996) relataram os efeitos do processamento, como a maceração em tempo médio de cocção entre 90-155 min. Maceração reduziu o tempo de cocção em 50\%, sendo o período de 12 horas o mais apropriado quanto à redução de tempo de cocção, taninos e fitatos. O teor encontrado foi de $0,081 \% \mathrm{mEq}$ catequina de feijão cozido, e para a maceração de 24 horas, o teor foi de $0,095 \% \mathrm{mEq}$ catequina de feijão cozido, tendo o controle (sem tratamento) o teor de $0,113 \% \mathrm{mEq}$ catequina. Weder et al. (1997), analisando feijão comum e feijão anasazi, encontraram 0,73 e $0,57 \% \mathrm{mEq}$ catequina.

Pinn (1992) certificou que o teor de fitatos no feijão cozido (Phaseolus vulgaris L.) variedade carioca irradiado diminuiu em função da dose de radiação; o teor controle (sem dose de radiação) de fitatos foi de $0,21 \mathrm{mg} / \mathrm{g}$, enquanto no feijão que recebeu dose de 20 kGy o teor foi de $0,14 \mathrm{mg} / \mathrm{g}$. 
De acordo Ologhobo \& Fetuga (1984), cocção e autoclavagem foram pouco eficientes na diminuição do conteúdo de fitatos em feijão. Concordando com a pesquisa de Ene-Obong \& Obizoba (1996), na qual o tratamento térmico não teve efeito no conteúdo de fitatos, sendo o teor de fitato do controle 7,61 mg/g, correspondendo, em média, com os valores encontrados (figura 3). Porém, a maceração por 12 horas apresentou o teor de 5,28 $\mathrm{mg} / \mathrm{g}$, ocasionando, uma redução de $31 \%$ do fitato, enquanto a maceração por 24 horas apresentou $6,43 \mathrm{mg} / \mathrm{g}$ de fitato com redução de $16 \%$ do fitato.

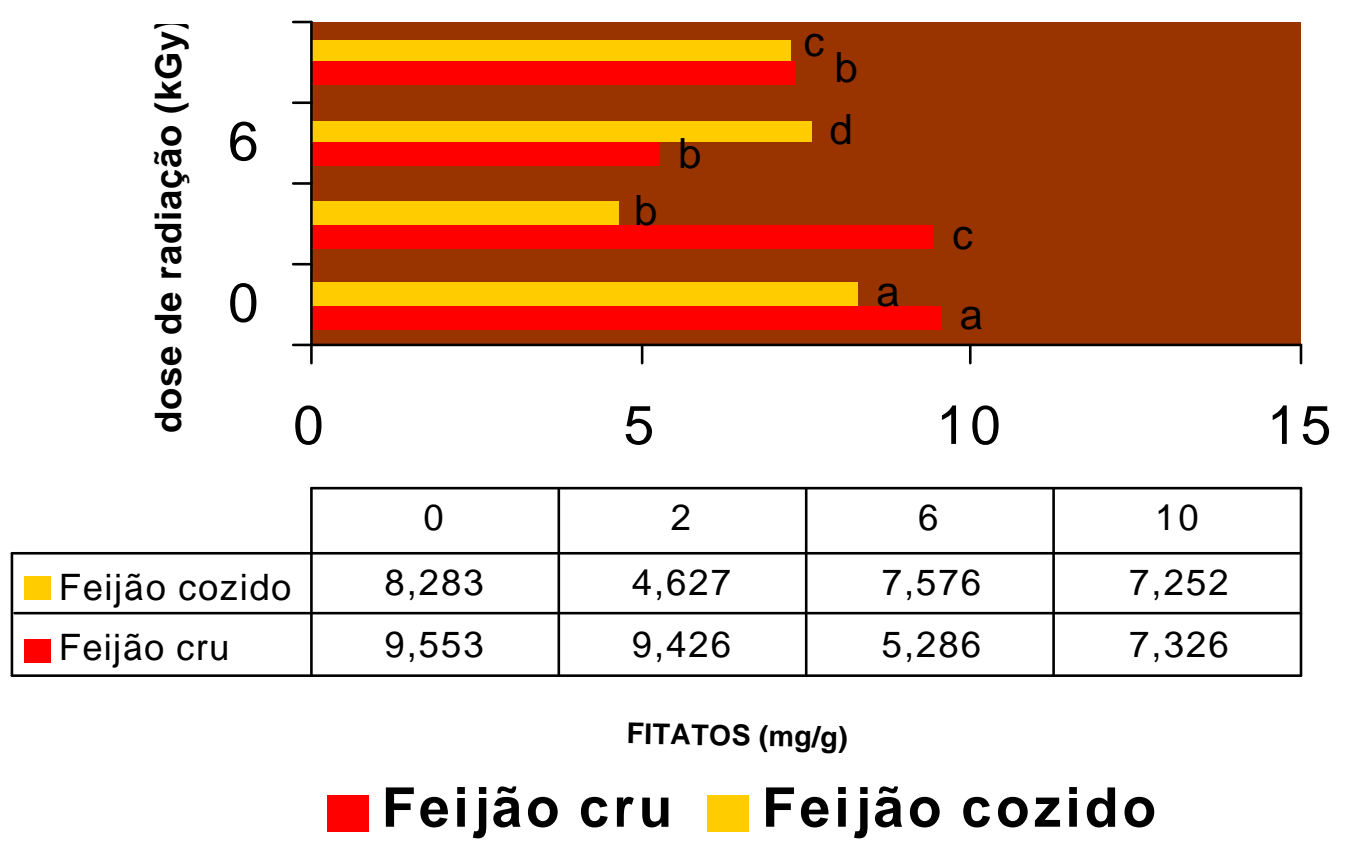

Figura 3 - Concentrações de fitatos dos feijões irradiados da variedade carioca Letras diferentes nas colunas de mesma cor diferem significativamente entre si $(\mathrm{p} \leq 0,05)$

Ene-Obong (1995) encontrou para Sphenostylis stenocarpa, feijão guandu (Cajanus cajan) e feijão de corda (Vigna unguiculata) a variação dos teores de fitatos 6,30-7,45 $\mathrm{mg} / \mathrm{g} ; 8,31-11,31 \mathrm{mg} / \mathrm{g} ; 8,40-9,92 \mathrm{mg} / \mathrm{g}$, respectivamente.

Em relação à disponibilidade do ferro "in vitro", nota-se que o tanto o feijão cru como o cozido tiveram o mesmo comportamento quanto às doses de radiação, mostrando que a dose de $6 \mathrm{kGy}$ apresenta resultados mais favoráveis em ambas as análises, embora o feijão cozido apresente porcentagem maior de diálise. 


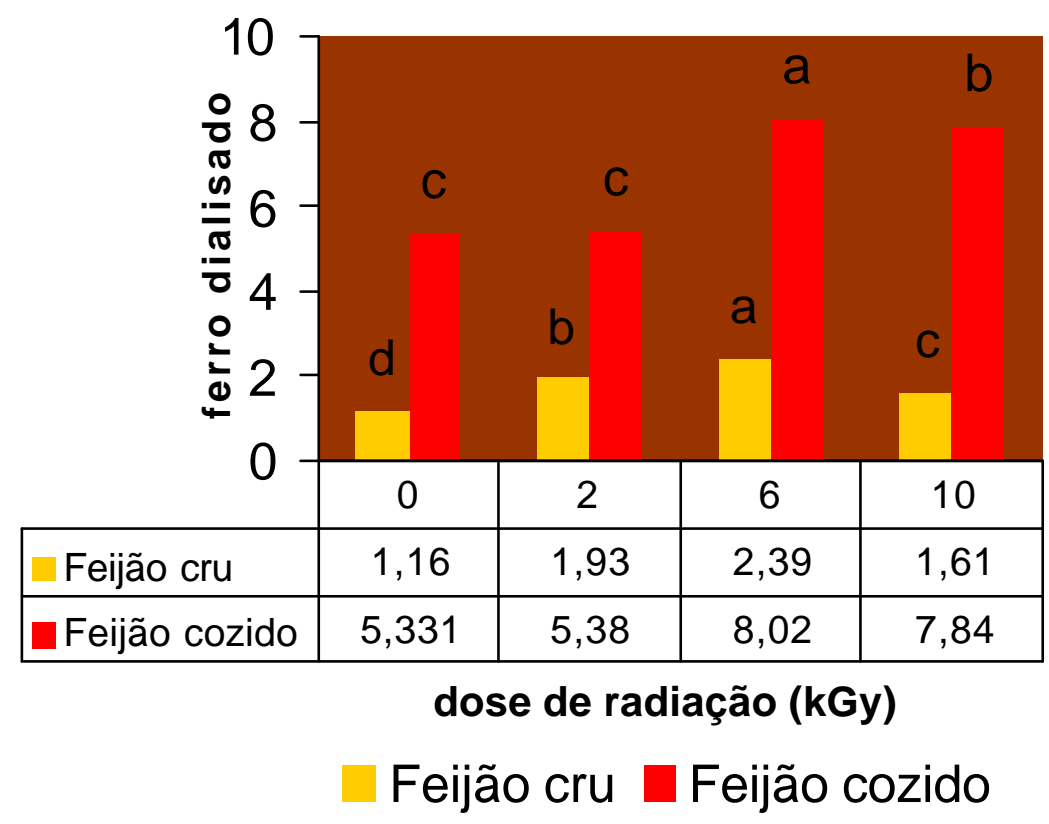

Figura 4 - Ferro dialisado em feijão cru e cozido irradiado (em \%)

Letras diferentes nas colunas de mesma cor diferem significativamente entre si $(p \leq 0,05)$

Considerando que a recomendação da ingestão de ferro possui, em média, 12,5 mg e a absorção para indivíduos saudáveis, corresponda a 15\% da quantidade do ferro total presente na dieta, verifica-se a importância do feijão comum na dieta da população brasileira, o qual, além de possuir excelentes propriedades nutricionais, favorece a classe sócio-econômica menos favorecida. Foi observado no feijão cru o benefício do efeito da irradiação no alimento tratado, com aumento no teor da diálise do ferro sob efeito da irradiação em relação ao controle. No feijão cozido, apresentou os processos de maceração e cocção como responsáveis pela inativação dos fatores antinutricionais, e conseqüentemente os melhores teores da diálise do ferro, além de assegurar textura, sabor e aroma para consumo.

Pinn (1992) verificou que, em função da dose empregada, ocorre amento da porcentagem de ferro dialisável; com doses de 2; 4; 6; 8 e 10 kGy observou aumentos de aproximadamente $11 \% ; 13 \%$; 23\%; $57 \%$ e $70 \%$ em relação à porcentagem de ferro dialisável do feijão não irradiado $(0,82 \%)$. 
Martínez et al. (1998) relataram que a disponibilidade do ferro "in vitro" em feijões cozidos para as variedades de Phaseolus vulgaris Cleo, Strike e Sentry apresentou as médias de 4,$1 ; 5,9 ; 9 \%$, sendo semelhantes às apresentadas na figura 4 .

Amaya et al. (1991) encontraram as seguintes variações de ferro total durante o processamento em feijão preto (Phaseolus vulgaris), feijão sem caldo 2,9-3,8 mg/100g, feijão com caldo 4,1-5,8 mg/100g e caldo de 12,6-15,5 mg/100g e o ferro ionizável como indicador da biodisponibilidade de ferro variou de 0,31-0,41 mg para feijão sem caldo e 0,29-0,41 mg para feijão com caldo, sendo esses valores próximos, porém o valor encontrado no caldo de feijão variou de 1,13-1,92 mg.

Sgarbieri et al. (1979), utilizando metodologia "in vivo", com ratos anêmicos, tendo como padrão sulfato ferroso, encontraram $4,05 \%$ de ferro biodisponível no feijão carioca cozido. As disponibilidades encontradas na presente pesquisa foram superiores, sendo que o método "in vitro" é comparável ao método de marcação extrínseca de ferro em humanos, segundo Miller \& Schricker (1982). 


\section{CONCLUSÕES}

$\mathrm{O}$ processo de irradiação com dose de $6 \mathrm{kGy}$ mostrou redução dos fatores antinutricionais em relação ao feijão cozido, sendo o mais efetivo para a disponibilidade do ferro.

Dessa forma, aliando os processos de irradiação (dose de 6 kGy) e cocção tem-se melhora na disponibilidade do ferro presente no grão, com consequente melhora no valor nutritivo, além de conferir conservação prolongada ao grão.

Pode-se concluir também que:

- houve alterações nos componentes da composição centesimal dos grãos após coç̧ão, como também após irradiação;

- a composição centesimal dos grãos cozidos apresentou diminuição nos teores de proteína, cinza e extrato etéreo, em comparação aos grãos crus;

- houve diminuição nos teores dos minerais com o processamento de cocção, com exceção do fósforo e cobre sendo que não hove alterações nos teores com a irradiação;

- o teor de taninos diminuiu com aumento da dose de radiação, assim como a cocção;

- o teor de fitato diminuiu com o processo de irradiação. 


\section{REFERÊNCIAS BIBLIOGRÁFICAS}

AHMED, M. Up-to-date status of food irradiation. Radiation Physics Chemistry, v.42, p.245-251, 1993.

AYKROID, W.R.; DOUGTHY, J. Legumes in human nutrition. Rome: FAO, 1982. 152p. (Food and Nutrition Paper, 20)

AMAYA, H.; ACEVEDO, E.; BRESSANI, R. Efecto del recalentamiento sobre la disponibilidad de hierro y el valor nutritivo de la proteina del frijol negro (Phaseolus vulgaris) cocido. Archivos LatinoAmericanos de Nutrición, v.41, n.2, p.222-237, 1991.

ANDERSON, B.M.; GIBSON, R.S.; SABRY, J.H. The iron and zinc status of longterm vegetarian women. American Journal of Clinical Nutrition, v.34, p.10421104, 1981.

ANDERSON, G. J. Control of iron absorption. Journal Gastroenterolgy Hepatology, v.11, p.1020-1032, 1996.

ANTUNES, P. L.; SGARBIERI, V.C. Fatores antinutricionais, toxicidade e valor nutricional do feijão comum (Phaseolus vulgaris L.). Agros, v.15, n.1, p.39-62, 1980. 
ANTUNES, P.L.; BILHALAVA, A .B.; ELIAS, M. C. et al. Valor nutricional de feijão (Phaseolus vulgaris, L.), cultivares rico 23, carioca, piratã-1 e rosinha-g2. Revista Brasileira de Agrociência, v.1, n.1, p.12-18, 1995.

ASSOCIATION OF OFFICIAL ANALYTICAL CHEMISTS. Official methods of analysis. 16. ed. Arlington, 1995. v.2, cap.32, p.22-23: Cereal foods.

BALLOT, D.; BAYNES, R. D.; BOTHWELL, T. H. et al. The effect of fruit juices and fruits on the absorption of iron from a rice meal. British Journal of Nutrition, v.57, p.331-343, 1987.

BENITO, P.; MILLER D. Iron absorption and bioavailability: an update review. Nutrition Research, v.18, n.3, p.581-603, 1998.

BIANCHI, M. L. P.; SILVA, H.C.; OLIVEIRA, J. E.D. Considerações sobre a biodisponibilidade do ferro dos alimentos. Archivos LatinoAmericanos de Nutrición, v.42, p.94- 100, 1992.

BOTHWELL, T.H.; BAYNES, R. D.; MACFARLANE, B. J. et al. Nutritional iron requirements and food iron absorption. Journal of International Medicine, v.226, p.357-365, 1989.

BRAVO, L.; ABIA, R.; GOÑI, I. et al. Possible common properties of dietary fibre constituents and polyphenols. European Journal of Clinical Nutrition, v. 49, suppl.3, p.211-214, 1995.

BRESSANI, R.; ELÍAS, L. G. Legume Foods. In: A.M. ALTSCUHL (Ed.). News protein foods. New York: Academic Press, 1974. p. 230-297. 
BRESSANI, R.; ELÍAS, L. G; BRAHAM, J. E. Reduction of digestibility of legume proteins by tannins. Journal of Plant Foods, v.4, p.34-55, 1982.

BRESSANI, R.; ELÍAS, L.G.; WOLZACK, A. Tannin in common beans methods of analysis and effects on protein quality. Journal of Food Science, v.48, p.1000$1003,1983$.

BRUNE, M.; ROSSANDER, L.; HALLBERG, L. Iron absorption and phenolic compounds: importance of different phenolic structures. Journal of Clinical Nutrition, v.43, p.547-558, 1989.

CANDELA, M.; ASTIASARAN, I.; BELLO, J. Cooking and warm holding: effect on general composition and aminoacids of kidney beans (Phaseolus vulgaris), chickpeas (Cícer aritinum) and lentils (Lens culinaris). Journal of Agricultural and Food Chemistry, v 45, n.12, p.4763-4767, 1997.

CANNIATTI-BRAZACA, S.G. Influência das modificações genéticas sobre as características físicas, químicas e nutricionais do feijão guandu (Cajanus cajan, L.). São Paulo, 1994. 167p. Tese (Doutorado) - Faculdade de Ciências Farmacêuticas, Universidade de São Paulo.

CANNIATTI- BRAZACA, S. G. Antinutricionais em alimentos. In: OETTERER, M. (Coord.). Processamento e qualidade nutricional dos alimentos: Palestras. Piracicaba: ESALQ, Depto de Ciência e Tecnologia Agroindustrial, 1997. p. 1-23.

CANNIATTI- BRAZACA, S.G.; SILVA, F. C. da Avaliação do aproveitamento do ferro de leguminosas por diálise "in vitro" In: CONGRESSO NACIONAL DA SOCIEDADE BRASILEIRA DE ALIMENTAÇÃO E NUTRIÇÃO, 5., São Paulo, 1999. Resumos. São Paulo: SBAN, 1999. p.258. 
CARPENTER, C. E; MAHONEY A .W. Contributions of heme and nonheme iron to human nutrition. Critical Review of Food Science and Nutrition, v.31, n.4, p.333367, 1992.

CARNOVALE, E.; LINTAS, C. Dietary fibre; Effect of processing and nutrient interactions. European Journal of Clinical Nutrition, v.49, suppl. 3, p. 307-311, 1995.

CHAUD, M. V.; FREITAS, O. Compostos alternativos para o tratamento e/ou prevenção da anemia ferropriva. Cadernos de Nutrição, v.8, p.1-9, 1994.

CLYDESDALE, F. M. Minerals: their chemistry and fate in food. In: SMITH K.T. (Ed). Trace minerals in food, New York: Marcel Dekker, 1988. p.57-94.

CLYDESDALE, F. M.; HO, C.T; LEE, C.Y et al. The effects of postharvest treatment and chemical interactions on the bioavaibility of ascorbic acid, thiamin, vitamin A, carotenoids, and minerals. Critical Review Food Science and Nutrition, v.30, p.599-638, 1991.

CONRAD, M.E.; UMBREIT, J.N.; MOORE, E.G. A role for mucin in the absorption of inorganic iron and other metal cations. Gastroenterology, v.100, p.129-136, 1991.

COOK, J. D. Absorption of food iron. Federation Proceedings, v.36, n.7, p.2028-2032, 1977.

COOK, J. D.; REDDY, M. B.; BURRI, J. et al. The influence of different cereal grains on iron absorption from infant cereal foods. American Journal of Clinical Nutrition, v.65, p.964-969, 1997 
CUNHA, M. F.; SGARBIERI, V.C.; DAMÁSIO, M. H. Effects of pretreatment with gamma rays or microwave on storage stability of dry beans. Journal of Agricultural and Food Chemistry, v.41, n.10, p.1710-1715, 1993.

DELLA PENA, D. Nutritional genomics: manipulating plant micronutrients to improve human health. Science, v.285, p.375-379, 1999.

DELINCÉE, H.; VILLAVICENCIO, A. N.C. H.; MANCINI-FILHO, J. Protein quality of irradiated brazilian beans. Radiation Physics and Chemistry, v.52, n.1-6, p.4347, 1998.

De MAYER E. M; DALLMAN P.; GURNEY J. M et al. Preventing and controlling iron deficiency anaemia trough primary health care. Geneva: WHO, 1989. (A Guide for Health Administrators and Programme Managers).

DE VIZIA B, POGGI V, VAJRO P. et al. Iron malabsorbtion in giardisis. The Journal of Pediatrics, v.107, n.1, p.75-78, 1995.

DESPHPANDE, S. S.; SATHE, S. K.; SALUNKHE, D. K. et al. Effects of dehulling on phytic acid, polyphenols and enzyme inhibitors of dry beans. Journal of Food Science, v.47, p.1846-1850, 1982.

DIEHL, J. F. Safety of irradiated foods. New York: Marcel Decker, 1995. 454 p.

DISLER, P.B.;LYNCH, S. R.; CHARLATAN, R. W. et al. The effect of tea on iron absorption. Gut British Society of Gastroenterology, v.16, p.193-200,1975.

ELPO, E. R. S.; FREITAS, R. J. S.; GOMES, E.C. Avaliação dos teores de ferro nos alimentos da cesta básica. Archivos LatinoAmericanos de Nutrición, v.48, n.1, p.65-67,1998. 
ENE-OBONG, H.N. Content of antinutrie nts and in vitro protein digestibility of the African yambean, pigeon and cowpea. Plant Food for Human Nutrition, v.48, p. 223-225, 1995.

ENE-OBONG, H.N.; OBIZOBA, I.C. Effect of domestic processing on the cooking time, nutrients, antinutrients and in vitro protein digestibility of the African yambean (Sphenostylis stenocarpa). Plant Food for Human Nutrition, v.49, p.43$52,1996$.

FAIRBANKS, V.F. Iron in medicine and nutrition. In: SHILS, M.E, OLSON, J.A; SHIKE, M. (Ed.). Modern nutrition in health and disease. Philadelphia: Lea and Febiger, 1994. p.185-213.

FAIRWEATHER-TAIT, S. J.; WRIGHT, A. J. A. Small intestine transit time and iron absorption. Nutrition Research, v.11, p.1465-1468, 1991.

FAIRWEATHER-TAIT, S. J. Bioavailability of trace elements. Food Chemistry, v.43, p.213-217, 1992.

FAIRWEATHER-TAIT, S. J. Bioavaibility of nutrients. In: MACRAE, R.; ROBINSON, R.K.; SADLER, M. J. Encyclopedia of food science food technology and nutrition. London: Academic Press, 1993. p.384-388.

FAIRWEATHER-TAIT, S. J.; FOX T. E.; WHARF S. G. et al. The bioavailability of iron in different weaning foods and the enhancing effects of a fruit drink containing ascorbic acid. Pediatric Research, v.37, n.4, p.389-394, 1995.

FAO. General standard for irradiated foods. Rome, 1983 (Codex Alimentarius, 15). 
FAO. Requirements of vitamin $\mathbf{A}$, iron, folate, and vitamin $\mathbf{B}_{12}$ : report of a Joint FAO/OMS Expert Consultation. Rome, 1988, (FAO Food and Nutrition Series, 23)

FAO. Codex alimentarius: requisitos generales. Roma, 2000. 300p.

FIGUEIREDO, M. S.; KERBAUY, J. Anemias. In: PRADO, F .C. do; RAMOS, J.R.; VALLE; J.R. Manual prático de diagnóstico e tratamento. 17.ed. São Paulo: Artes Médicas, 1995. cap.6. p.371-372.

FUNDAÇÃO INSTITUTO BRASILEIRO DE GEOGRAFIA E ESTATÍSTICA. Anuário estatístico do Brasil. Rio de Janeiro, 1996. v.56, p.3-53: Produção vegetal.

FUNDAÇÃO INSTITUTO BRASILEIRO DE GEOGRAFIA E ESTATÍSTICA. http://www1.ibge.gov/br/ibge/estatística/indicadores/agropecuaria/Ispa/default.shtm (19 julho 2001).

FROLICH, W. Bioavailability of micronutrients in a fibre-rich diet, especially related to minerals. European Journal of Clinical Nutrition, v.49, suppl. 3, p.116-122, 1995.

GARCÍA-CASAL, M. N.; LAYRISSE, M.; SOLANO, L. et al. Vitamin A and $\beta$ carotene can improve nonheme iron absorption from rice, wheat and corn by humans. Journal of Nutrition, v.128, p.646-650, 1998.

GEIL , P.B.; ANDERSON, J.W. Nutrition and health implications of dry beans: a review. Journal of the American College of Nutrition, v 13, n 6, p.549-558, 1994.

GIBSON, R.S. Content and bioavaibility of trace elements in vegetarian diets. American Journal of Clinical Nutrition, v.59, suppl. 5, p.1223-12232, 1994. 
GILLOOLY, M.; BOTHWELL, T.H.; CHARLTON, R.W. et al. Factors influencing the absorption of iron from cereals. British Journal of Nutrition, v.51, n.1, p.37-46, 1984.

GLEERUP, A.; ROSSANDER-HULTÉN, L.; GRAMATKOVSKI, E. et al. Iron absorption from the whole diet: Comparison of the effect of two different distributions of daily calcium intake. American Journal of Clinical Nutrition, v.61, n.3, p.97-104, 1995.

GONÇALVES, J.S.; SOUZA, S.A.M. Gangorra de preços: a produção e o abastecimento de feijão na safra 1997/98 no Estado de São Paulo. Informações Econômicas, v. 28, n.6, p.60-65, 1998.

GONZÁLES, G.C.A. Efecto del tratamiento térmico sobre el contenido de fibra dietética total, soluble e insoluble en algunas leguminosas. Archivos Latinoamericanos de Nutrición, v.50, n.3, p.281-285, 2000.

GOYCOOLEA, F.; MEJÍA, E.G.; BARRÓM, J.M. et al. Efecto de los tratamientos caseros en la preparacion de frijol pinto (Phaseolus vulgaris) sobre el contenido de taninos y valor nutritivo de las proteínas. Archivos Latinoamericanos de Nutrición, v.40, n.2, p.263-274, 1990.

GRYNSPAN, F.; CHERYAN, M. Phytate-calcium interaction with soy protein. Journal of the American Oil Chemists Society, v.66, n.1, p.93-97, 1989.

GUYTON, A.C. Fisiologia humana e mecanismos das doenças. 4: ed. Rio de Janeiro: Guanabara, 1989. cap.5, p.165-166: Células sangüíneas, imunidade e coagulação sanguiínea. 
GUZMÁN- MALDONADO, S.H.; ACOSTA-GALLEGOS, J.; PAREDE-LÓPES, O. Protein and mineral content of a novel collection of wild and weedy commom beans (Phaseolus vulgaris L.). Journal of the Science of Food and Agriculture, v.80, p.1874-1881, 2000.

HAYASHI, T. Food Irradiation. London: Stuart Thorne, 1991.p. 169-203. Comparative effectiveness of gamma-rays and electron beams in food irradiation.

HAllberG, L. Bioavaibility of dietary iron in man. Annual Review of Nutrition, v.1, p.123-147, 1981.

HALLBERG, L.; BRUNE, M.; ROSSANDER, L. Effect of ascorbic acid on iron absorption from different types of meals. Studies with ascorbic acid-rich foods and synthetic ascorbic acid given in different amounts with different meals. Human Nutrition Applied Nutrition, v.40, n.1, p.97-113, 1986.

HALLBERG, L.; ROSSANDER-HULTHÉN, L.; BRUNE, M. et al. Calcium and iron absorption: mechanism of action and nutritional importance. European Journal of Clinical Nutrition, v.46, p.317-327, 1992.

HALLBERG, L.; ROSSANDER-HULTHÉN, L.; BRUNE, M. et al. Inhibition of haemiron absorption in man by calcium. British Journal of Nutrition, v.69, n.2, p.533$540,1993$.

HAMBRAEUS L. Animal and plant food based diets and iron status: benefits and costs. Proceedings of the Nutrition Society, v.58, p.235-242, 1999.

HAZELL, T.; JOHNSON, I.T. In vitro estimation of iron availability from a range of plant foods: influence of phytate, ascorbate and citrate. British Journal of Nutrition, v.57, n.2, p.223-233, 1987. 
HERRERA, I.M.; GONZÁLES, E.P.; ROMERO, J.G. Fibra dietética soluble: insoluble total en leguminosas crudas e cocidas. Archivos Latinoamericanos de Nutrición, v. 48, n.2, p.179-181, 1998.

HOUSE, W.A. Trace element bioavailability as exemplified by ron and zinc. Field Crops Research, v.60, p.115-141, 1999.

HOUSE, W. A.; WELCH, R.M. Bioavaibility to rats of iron in six varieties of wheat grain intrinsically labeled with radioiron. Journal of Nutrition, v.117, p.476-480, 1987.

HURRELL, R.F; LYNCH, SR.; TRINIDAD, T.P.et al. Iron absorption in humans: bovine serum albumin compared with beef muscle and egg white. American Journal of Clinical Nutrition, v.47, p.102-107, 1988.

INTERNATIONAL ATOMIC ENERGY AGENCY (IAEA). Use of irradiation as a quarantine treatment of food and agricultural commmodities. Vienna, 1985. $66 \mathrm{p}$.

KARMAS, E.; HARRIS, R.S. Nutritional evaluation of food processing. New York: Van Nostrand Reinhold, 1988. 786p.

KRATZER, F.H.; VOHRA, P. Chelates in nutrition. Boca Raton: CRC Press, 1986. 169 p.

LARSEN, T. Interactions between minerals: Comparison between mineral absorption in rat and pig. In: JUNGVID H.; FORSHELL, L.P.; EGGUM B.O. (Ed) The rat as a model for man and pig in nutritional and physiological studies. Tjele: National Institute of Animal Science, 1992. p.137-142. 
LINDER, M.C. Nutrición. Aspectos bioquímicos, metabólicos y clínicos. Eunsa: Pamplona , 1988. p.189-216: Nutrición y metabolismo de los elementos traza.

LOLAS, G.M.; MARKAKIS, P. Phytic acid and other phosphorus compounds of beans (Phaseolus vulgaris L.). Journal of Agricultural and Food Chemistry, v.23, n.1, p.13-16, 1975.

LUTEN, J.; CREWS, H.; FLYNN, A. et al. Interlaboratory trial on the determination of the In vitro iron dialysability from food. Journal of the Science of Food and Agriculture, v.72, n.4, p.415-424, 1996.

MALDONADO, S.; SAMMÁM, N. Composición química y contenido de minerales de leguminosas y cereales producidos en el noroeste argentino. Archivos LatinoAmericanos de Nutrición, v.50, n.2, p.195-199, 2000.

MANCINI-FILHO, J. Efeitos das radiações gama sobre algumas características físicoquímicas e nutricionais de feijões (Phaseolus vulgaris L.) armazenados. São Paulo. 1990. 100p. Tese (Livre Docência) - Faculdade de Ciências Farmacêuticas, Universidade de São Paulo.

MARQUES, C.; LIZZOT, C.; SILVA, P.R. et al. Deficiência de ferro na população carente de Porto Alegre. Revista Brasileira de Analíses Clinícas, v.30, n.2, 1998.

MARTIN-CABREJAS, M.A.; ESTEBAN, R.M.; PEREZ, P.et al. Changes in physicochemical properties of dry beans (Phaseolus vulgaris L.) during long-term storage. Journal of Agriculture Food Chemistry, v.45, p.3223-3227, 1997. 
MARTÍNEZ, C.; ROS, G.; PERIAGO, M. J. et al. In vitro protein digestibility and mineral avaibility of green beans (Phaseolus vulgaris L.) as influenced by variety and pod size. Journal of the Science of Food and Agriculture, v.77, p.414-420, 1998.

MARTÍNEZ, C.; ROS G.; PERIAGO, M.J. et al. Biodisponibilidad del hierro de los alimentos. Archivos LatinoAmericanos de Nutrición, v.49, n.2, p.106-113, 1999.

MIGITA, S. The effects of food ingredients on non-heme iron absorption in rats and the inhibitory mechanism of soy protein isolate. Journal of Nippon Medical School, v.55, p.555-563, 1988.

MILLER. D.; SCHRICKER, B. In vitro estimation of food iron bioavailability. In: KIES C. (Ed.). Nutritional biovailability of iron. Washington: American Chemical Society, 1982. cap. 2, p.11-26. (ACS Symposium Series, 203).

MILLER, D.; SCHRICKER, B.; RASMUSSEN, R. et al. An in vitro method for estimation of iron availability from meals. American Journal of Clinical Nutrition, v.34, p. 2248-2256, 1981.

MINIHANE, A.M.; FOX, T.E.; FAIRWEATHER-TAIT, S.J. A continuos flow in vitro method to predict bioavailability of Fe from foods. Proceedings Biology, v.2, p.175-179, 1993.

MITJAVILA, S.; LACOMBE, C.; CARRERA, G.et al. Tannic acid and oxidized tannic acid on the functional state of rat intestinal epithelium. Journal of Nutrition, v.107, n.12, p. 2113-2121, 1977. 
MOLINA, M.R.; FUENTE, G. de la; BRESSANI, R. Interelationships between storage, soaking time, cooking time, nutritive value and other characteristics of the black bean (Phaseolus vulgaris). Journal of Food Science, v.40, p.587-591, 1975.

MONSEN E.R. Ascorbic acid: an enhancing factor in iron absorption. In: KIES, C. (Ed.) Nutritional bioavaibility of iron. Washington: American Chemistry Society, 1982, p.85-95. (American Chemical Society Symposium, 203)

MONSEN, E.R.; HALLBERG, L.; LARISSE, M. et al. Estimation of available dietary iron. American Journal of Clinical Nutrition, v.31, p.134, 1978.

MORRIS, E.R. Iron. In:MERTZ, W. (Ed). Trace elements in human and animal nutrition. New York: Academic Press, 1987. v.1, p.79-141.

NASCIMENTO, L.M. Efeito da radiação gama $\left({ }^{60} \mathrm{Co}\right)$ nas propriedades físico-químicas e sensoriais de feijões envelhecidos (Phaseolus vulgaris). São Paulo, 1992. 135p. Tese (Doutorado) - Faculdade de Ciências Farmacêuticas, Universidade São Paulo.

NATIONAL RESEARCH COUNCIL. Recommended dietary allowances. 10. ed. Washington: National Academic Press, 1989. p.284.

NIELSEN, F.H. Other elements: Sb, Ba, B, Br, Cs, Ge, Rb, Ag, Sr, Sn, Ti, Zr, Be, Bi, $\mathrm{Ga}, \mathrm{Au}, \mathrm{In}, \mathrm{Nb}, \mathrm{Sc}, \mathrm{Te}, \mathrm{Tl}, \mathrm{W}$. In: MERTZ, W. (Ed.). Trace elements in human and animal nutrition. New York: Academic Press, 1986. v.2, p.415-488.

OLIVEIRA, H. P. Hematologia clínica. 3. ed. Rio de Janeiro: Atheneu, 1990. p.105121. 
OLOGHOBO, A.D.; FETUGA, B.L. Effect of processing on the trypsin inhibitor, haemagglutinin, tannic acid and phytic acid contents of seeds of ten cowpea varieties. Tropical Agriculture, v.61, n.4, p.261-264, 1984.

ORGANIZACIÓN MUNDIAL DE LA SALUD. Lucha contra la anemia nutricional, especialmente contra la carencia de hierro. Ginebra, 1975. (OMS Serie de Informes Tecnicos, 580)

PANT, R.; TULSIANI, D. R. P. Solubility, amino acid composition, and biological evaluation of proteins isolated from leguminous seeds. Journal of Agriculture Food Chemistry, v.17, p.361, 1969.

PAREDE- LOPEZ, O.; HARRY, G.I. Food biotechnology review: tradicional solid state fermentations of plant raw material: application nutritional aignificance and future prospects. Critical Reviews Food Science and Nutrition, v.27, p.159, 1988.

PAREDE-LOPEZ, O.; HARRY, G.I. Changes in selected chemical and antinutritional components durring tempeh preparation using fresh and hardened commom beans. Journal of Food Science, v.54, n.4, p.968-970, 1989.

PASSMORE, R.; NICOL, B.M.; RAO, M.N. Manual das necessidades nutricionais humanas. Rio de Janeiro: Livraria Atheneu Editora, 1986. p.55-59: Ferro.

PETERS, T.J.; RAJA, K.B.; SIMPSON, R.J. Speciation of trace metals, with special reference to intestinal iron absorption. Food Chemistry, v.43, p.315-320, 1992.

PIMENTEL - GOMES, F. Curso de estatística experimental . 10. ed. São Paulo: Nobel, 1982. 468p. 
PINN, A.B.R.O. Efeitos das radiações gama sobre a disponibilidade do ferro em feijões (Phaseolus vulgaris). São Paulo, 1992. 129 p. Dissertação (Mestrado) - Faculdade de Ciências Farmacêuticas, Universidade de São Paulo.

POLTRONIERI, F.; ARÊAS, J.A.G.; COLLI, C. Extrusion and iron bioavailability in chickpea (Cicer arietinum L.). Food Chemistry, v.70, p.175-180, 2000.

PRICE, M.L.; HAGERMAN, A .E.; BUTLER, L.G. Tannin content of cowpeas, chickpeas, pigeon peas, and human mung beans. Journal of Agriculture Food Chemistry, v.28, n.2, p.459-461, 1980.

PRICE, K.R.; SOUTHON, S.; FEWICK,G.R. The effect of saponins on iron and zincc avaibility. In: SOUTHGATE, D.A.T.; JOHNSON, I.T.; FEWIICK, G.R. (Ed.) Nutrients avaibility: chemical and biological aspects. Cambridge: Royal Society of Chemistry, 1989. p.155-157. (Special Publication, 72)

RAJA, K.B; SIMPSON, R.J.; PETERS, T.J. Membrane potential dependence of Fe (III) uptake by mouse duodenum. Biochemical Biophsical Acta, v.984, p.262-266, 1989.

RAJA, K.B; SIMPSON, R.J.; PETERS, T.J. Ferric iron reduction and uptake by mouse duodenal mucosa. Biochemical Society Transactions, v.19, n.3, p.316S, 1991.

REDDY, N.R.; SATTHE, S.K.; SALUNKHE, D.K. Phytates in legumes and cereals. Advances in Food Research, v.28, p.1-92, 1982.

REDDY, N.S.; PIERSON, M.D.; SATTHE, S.K.et al. Dry beans tannins: a review of nutritional implications. Journal American Oil Chemistry Society, v.62, p.54$549,1985$. 
REDDY, M.B; HURRELL, R.F; JUILLERAT, M. A. et al. The influence of different protein sources on phytate inhibition of nonheme-iron absorption in humans. American Journal of Clinical Nutrition, v.63, p.203-207, 1996.

ROSTON, A .J. Feijão. Campinas:CATI, 1990. 18 p. (Boletim Técnico, 199)

SALUNKHE, D.K.; CHAVAN, J.K.; KADAM, S.S. Dietary tannins : consequences and remedies. Boca Raton: CRC Press, 1990. 200 p.

SALUNKHE, D.K.; JADHAV, S.J.; KADAM, S.S. et al. Chemical, biochemical and biological significance of polyphenols in cereals and legumes. CRC Critical Reviews Food Science and Nutrition, v.17, n.3, p.277-305, 1982.

SAMMÁN, N.; MALDONADO, S.; ALFARO, M.E. et al. Composition of different bean varieties (Phaseolus vulgaris) of northwestern Argentina (region NOA): cultivation zone influence. Journal of Agriculture and Food Chemistry, v.47, n.7, p.2685-2689, 1999.

SARRUGE, J.R.; HAAG, H.P. Análises químicas em plantas. Piracicaba: ESALQ, 1974. 56p.

SATHE, S.K.; SALUNNKHE, D.K. Investigations on wingedbean Psophocarpus tetragonolobus (L.) proteins and antinutritional factors. CRC Critical Reviews Food Science and Nutrition, v.20, n.1, 1984.

SATHE, S.K.; DESHPANDE, S.S.; SALUNKHE, D.K. Dry beans of Phaseolus: a review I. Chemical composition . Protein. CRC Critical Reviews Food Science and Nutrition, v.20, n.5, p.31-39, 1984. 
SATHE, S.K.; DESHPANDE, S.S.; REDDY, N.R. et al. Effects of germination on proteins, raffinose, oligosacharides, and nutritional factors in the great Northern beans (Phaseolus vulgaris L.). Journal of Food Science, v.48, n.6, p.1796-1800, 1983.

SCHNEEMAN. B.O.; TIETYEN, J. Dietary fiber. In: SHILS, M.E.; OLSON, J.A.,SHIKE, M. (Ed.) Modern nutrition in health and disease. Philadelphia: Lea and Febiger, 1994. p.89-100.

SCHRICKER, B.R.; MILLER , D.D; VAN CAMPEN, D. In vitro estimation of iron avaibility in meals containing soy products. Journal of Nutrition, v.112, n.9, p.1696-1705, 1982.

SGARBIERI, V.C.; WHITAKER, J.R. Physical, chemical and nutritional properties of commom beans (Phaseolus) proteins. Advances in Food Research, v. 28, p.93$163,1982$.

SGARBIERI, V.C.; ANTUNES, P.L.; ALMEIDA, L.D. Nutritional evaluation of four varieties of dry beans (Phaseolus vulgaris, L.). Journal of Food Science, v.44, 1306-1308, 1979.

SHAHKALILI, Y.; FINOT, P.A ; HURRELL, R. et al. Effects of food rich in polyphenols on nitrogen excretion in rats. Journal of Nutrition, v.120, n.4, p.346$352,1990$.

SIGULEM, D.M.; TUDISCO, E.S.; GOLDENBERG, P. et al. Anemia ferropriva em crianças no município de São Paulo. Revista de Saúde Pública, v.12, p.168-178, 1978. 
SILVA, V.R.; IACHAN, A. Proteins from varieties of Brazilian beans Phaseolus vulgaris)I Quantification and fractionation of proteins. Revista Brasileira de Tecnologia, v.6, p.133, 1975.

SIMPSON, R.J.; MOORE, R.; PETERS, T.J. Transpot of $\mathrm{Fe}^{2+}$ across lipid bilayers: Possible role of free fatty acids. Biochemical Biophsical Acta, v.898, p.187-195, 1988.

SIMPSON, R.J.; RAJA, K.B; PETERS, T.J. Evidence for distinct separately regulated mechanisms for the uptake of $\mathrm{Fe}^{2+}$ and $\mathrm{Fe}^{3+}$ by mouse duodenum. Biochemical Society Transactions, v.14, p.142, 1986.

SIMPSON, R.J.; VENKATESAN, S.; PETERS, T.J. Brush border membrane nonesterified fatty acids, phsiological levels and significance for mucosal iron uptake in mouse proximal intestine. Cell Biochemistry and Function, v.7, n.3, p.165-172, 1989.

SOUTHON, S.; FAIRWEATHER-TAIT J.; HAZELL T. Trace element availability from the human diet. Proceeding of the Nutrition Society, v.47, n.1, p.27-35, 1988.

STANLEY, D.W; AGUILERA, J.M. A review of textural defects in cooked reconstituided legumes: the influence of structure and composition. Journal of Food Biochemistry, v.9, n.4, p.277-323, 1985.

TOBIN, G.; CARPENTER, J. The nutritional value of the dry bean (Phaseolus vulgaris): a literature review. Nutrition Abstracts and Reviews Series A, v.48, n.11, p.919-936, 1978. 
TORRE, M.; RODRIGUEZ A .R.; SAURA-CALIXTO, F. Effects of dietary fiber and phytic acid on mineral availability. Critical Reviews Food Science and Nutrition,v.30, n.1, p.1-22, 1991.

TOTAL dietary fiber assay kit. Sigma Technical Bulletim, n. TDFAB-3, p.1-4, 2000.

UMMADI, P.; CHEMOWETH, W.L.; UEBERSAX, M.A. The influence of extrusion processing on iron dialyability, phytates and tannins in legumes. Journal of Food Processing Preservation, v.19, p.119-131, 1995.

UNIVERSIDADE DE SÃO PAULO. Faculdade de Ciências Farmacêuticas. Tabela de composição de alimentos. http://www.fcf.usp.br.2001, (11/06/2001)

VAN DOKKUM, W. Significance of iron bioavaibility for iron recommendations. Biological Trace Element Research, v.35, p.1-11, 1992.

VIEIRA, C. Leguminosas de grãos : importância na agricultura e na alimentação humana. Informe Agropecuário, v.16, n.174, p.5-11, 1992.

VILLAVICENCIO, A.L.C.H. Avaliação dos efeitos da radiação ionizante de ${ }^{60} \mathrm{Co}$ em propriedades físicas, químicas e nutricionais dos feijões Phaseolus vulgaris L. e Vigna unguiculata (L.) Walp. São Paulo, 1998. 138p. Tese (Doutorado) - Faculdade de Ciências Farmacêuticas, Universidade de São Paulo.

VILLAVICENCIO, A.L.C.H; MANCINI-FILHO, J.; DELINCÉE, H. et al. Effect of irradiation on anti-nutrients (total phenolics, tannins and phytate) in Brazilian beans. Radiation Physics and Chemistry, v.57, p.289-293, 2000.

YIP, R. Iron deficiency: contemporary scientific issues and international programmatic approaches. Journal of Nutrition, v.124, p.1479-1490, 1994. 
WEDER, J.K.P.; TELEK, L.; VOZÁRI-HAMPE, M. et al. Antinutritional factors in anasazi and other pinto beans (Phaseolus vulgaris L) Plants Foods for Human Nutrition, v.51, p.85-98, 1997.

WELCH, R.M.; HOUSE, W.A.; ALLAWAY, W.H. Effects of oxalic acid on availability of zinc from spinach leaves and zinc sulfate to rats. Journal of Nutrition, v.104, p.733-740, 1973.

WISE, A. Phytate and zinc bioavailability. Journal of Food Science and Nutrition, v.46, n.1, p.53-63, 1995. 